Supporting Information

For

\title{
Proline Isomerization-Regulated Tumor Microenvironment- Adaptable Self-Assembly of Peptides for Enhanced Therapeutic Efficacy
}

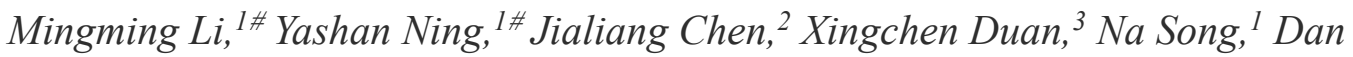 \\ Ding, ${ }^{3 *}$ Xuncheng $\mathrm{Su},{ }^{2 *}$ Zhilin $\mathrm{Yu}^{1 *}$
}

${ }^{1}$ Key Laboratory of Functional Polymer Materials, Ministry of Education, State Key Laboratory of Medicinal Chemical Biology, Institute of Polymer Chemistry, College of Chemistry, Nankai University, Tianjin 300071, China

${ }^{2}$ State Key Laboratory of Elemento-organic Chemistry, College of Chemistry, Nankai University, Tianjin 300071, China

${ }^{3}$ State Key Laboratory of Medicinal Chemical Biology, Key Laboratory of Bioactive Materials, Ministry of Education, and College of Life Sciences, Nankai University, Tianjin, 300071 China 


\section{CONTENTS:}

1. General Materials

2. Peptide Synthesis

3. Circular Dichroism (CD) Spectroscopy

4. Atom Force Microscopy (AFM)

5. Transmission Electron Microscopy (TEM)

6. Thioflavin T (ThT) Binding Assay

7. NMR Studies of Conformer of Xaa-Pro/Amp Amide Bonds

8. UV-vis Absorption Spectroscopy

9. Singlet Oxygen Generation Detection in Vitro

10. Intracellular ROS Generation

11. In Vitro Cytotoxicity Assay

12. Cellular Uptake Pathway of TMRS and TMAS

13. Bio-TEM Studies of Intracellular Morphology

14. Ex and in Vivo Fluorescence Imaging

15. In Vivo Blood Clearance Kinetic Studies

16. In Vivo Therapeutic Efficacy 


\section{General Materials}

2-Chlorotrityl chloride resin (loading density: $0.5 \mathrm{mmol} / \mathrm{g}$ ) was purchased from ApexBio Technology Co., Ltd. Fmoc-Phe-OH, Fmoc-Pro-OH, Boc-(2S, 4S)-4-amino1-Fmoc-pyrroliddine-2-carboxylic acid, N, N'-diisopropylethylamine (DIEA) and hexafluorophosphate azabenzotriazole tetramethyl uronium (HATU) used in solidphase peptide synthesis were acquired from Bide Pharmatech Co., Ltd. Trifluoroacetic acid (TFA) and triisopropylsilane were obtained from Meryer Chemical Technology Co. Ltd. Dichloromethane $\left(\mathrm{CH}_{2} \mathrm{Cl}_{2}\right)$, methanol $\left(\mathrm{CH}_{3} \mathrm{OH}\right)$ and $\mathrm{N}, \mathrm{N}$ '-dimethylformamide (DMF) were supplied by Tianjin Concord Technology Co., Ltd. Piperidine were obtained from Sinopharm Chemical Reagent Co., Ltd. Chlorin e6 (Ce6) was provided by Heowns Biochemical Technology Co., Ltd. Thioflavin T (ThT) and 1, 3Diphenylisobenzofuran (DPBF) were purchased from J\&K Scientific Ltd. 3-(4, 5Dimethylthiazol-2-yl)-2, 5-diphenyltetrazolium bromide (MTT), 2', 7'dichlorofluorescein diacetate (DCFH-DA) and 4', 6-diamidino-2-phenylindole (DAPI) were obtained from Sigma-Aldrich. Lysotracker Green DND-26 was supplied by Dalian Meilun Biotech Co., Ltd. All reagents were analytical grade. Ultrapure water was produced by Arium Pro Ultrapure water systems (Sartorius, 18.2 M $\Omega$ ).

\section{Peptide Synthesis}

\subsection{Synthesis of AmpF and $\mathbf{P F}$}

Peptides AmpF and PF were synthesized via standard Fmoc solid-phase peptide synthesis (SPPS) method. 2-chlorotrityl chloride resin was swelled in anhydrous $\mathrm{CH}_{2} \mathrm{Cl}_{2}$ for $30 \mathrm{~min}$. Then a mixture of Fmoc-Phe-OH (4 eq. relative to resin), DIEA (6 eq.), and $\mathrm{HATU}$ (4 eq.) in anhydrous $\mathrm{CH}_{2} \mathrm{Cl}_{2}$ was added to 2-chlorotrityl chloride resin. After $1 \mathrm{~h}, \mathrm{CH}_{3} \mathrm{OH}$ was added and shaken for another $30 \mathrm{~min}$ to terminate the resin sealing process. The sealed resin was successively washed by $\mathrm{DMF}, \mathrm{CH}_{3} \mathrm{OH}$, and $\mathrm{CH}_{2} \mathrm{Cl}_{2}$. Afterwards, amino acid coupling reactions were carried out by dissolving a mixture of amino acid / HBTU / DIEA ( $4: 3.95: 6$ relative to the resin) in DMF. Fmoc deprotection was performed in the presence of piperidine in DMF (25\%) solution for 
20 min. Peptides were cleaved from the resin using a cocktail of $95 \%$ trifluoroacetic acid, $2.5 \%$ triisopropyl silane, and $2.5 \% \mathrm{H}_{2} \mathrm{O}$ for $1 \mathrm{~h}$. The peptide solution was concentrated by rotary evaporation and precipitated by cold diethyl ether to obtain the crude peptide. The crude peptide was further purified by preparative reversed phase high performance liquid chromatography (RP-HPLC) with the gradient from "5\% acetonitrile+ $95 \%$ water" to "95\% acetonitrile $+5 \%$ water" as eluting solvents in a flow rate of $10 \mathrm{~mL} / \mathrm{min}$. The structures and purities of the purified AmpF and PF were characterized by mass spectrometry (Waters SQ Detector 2) and analytical HPLC (Agilent 1260), respectively.

\subsection{Synthesis of AmpF-C and PF-C}

Peptides AmpF-C and PF-C were prepared by covalently connecting chlorin e6 to the N-terminal amine groups of AmpF or PF in solid phase synthesis. A mixture of chlorin e6 (4 eq. relative to resin), DIEA (6 eq.) and HATU (4 eq.) was added to $\mathrm{NH}_{2}-\mathbf{A m p F}$ resin or $\mathrm{NH}_{2}$-AmpF-resin and shaken for $1.5 \mathrm{~h}$. The resin was successively washed by DMF, $\mathrm{CH}_{3} \mathrm{OH}$, and $\mathrm{CH}_{2} \mathrm{Cl}_{2}$ to remove excess reagents. Cleaving the targeting sequences from resins by the cocktail containing 95\% TFA for $1 \mathrm{~h}$ led to the crude product solution, which was concentrated by rotary evaporation and precipitated by cold diethyl ether. The crude peptide was further purified by RP-HPLC and characterized by mass spectrometry (Waters SQ Detector 2) and analytical HPLC (Agilent 1260), respectively.

\subsection{Preparation of TMAS and TMRS}

To prepare TMAS or TMRS solutions, the solution with a concentration of $10 \mathrm{mM}$ of peptides AmpF, AmpF-C, PF, or PF-C was initially prepared by dissolving the lyophilized peptide powder in basic water mediated by ammonium hydroxide. Mixing the solution of peptides AmpF and AmpF-C in a volume ratio of 4:1 and adjusting the solution $\mathrm{pH}$ to $7.4,6.5$, and 5.5 using hydrogen chloride led to the stock solutions of TMAS under various $\mathrm{pH}$ conditions with a concentration of $2 \mathrm{mM}$ after quantifying the 
solution volume with water, whereas utilization the solutions of peptides PF and PF-C gave rise to the TMRS stock solutions via the identical protocol. It is worth noting that due to their limited solubility in water, we were not able to prepare the solution of AmpF-C or PF-C with a concentration of $2 \mathrm{mM}$ identical to that of the solution of peptide AmpF or PF used in this work. To address the solubility issue, we coassembled AmpF with AmpF-C at a saturated concentration (0.4mM) under neutral condition, leading to a solution of TMAS at a total peptide concentration of $2 \mathrm{mM}$. Thus the molar ratio of AmpF and AmpF-C in the TMAS systems is 4:1. In addition, to maintain the maximal content of photosensitizer in the TMAS systems, we did not investigate the assembling behavior and cancer therapy of the co-assemblies of AmpF and AmpF-C with a content of lower than 20\%. This protocol was used to prepare TMRS systems by maintaining the molar ratio of PF and PF-C as 4:1. The stock solutions of TMAS and TMRS were aged for 2 days for thermodynamic equilibration prior to all the corresponding characterizations.

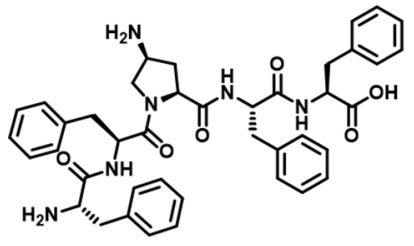

AmpF

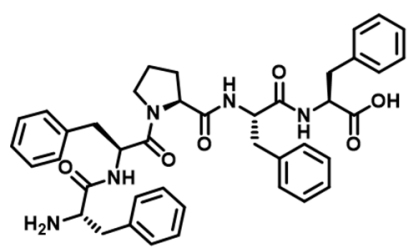

PF

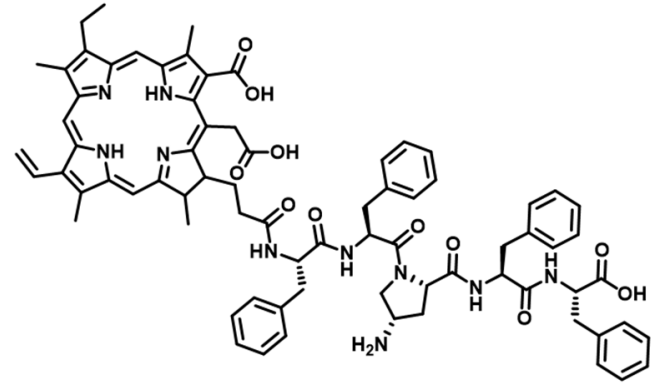

AmpF-C

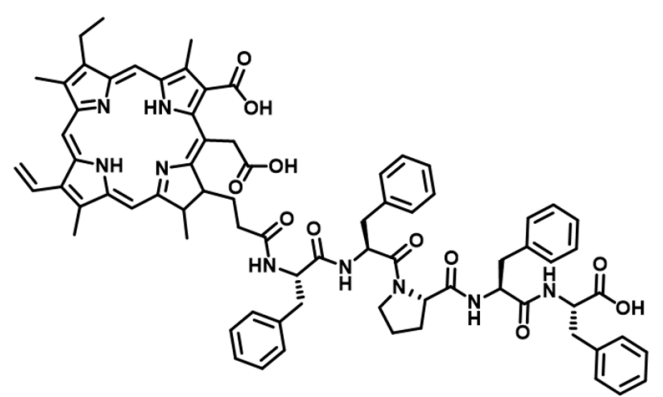

PF-C

Figure S1. Chemical structures of peptides AmpF, PF, AmpF-C, and PF-C. 


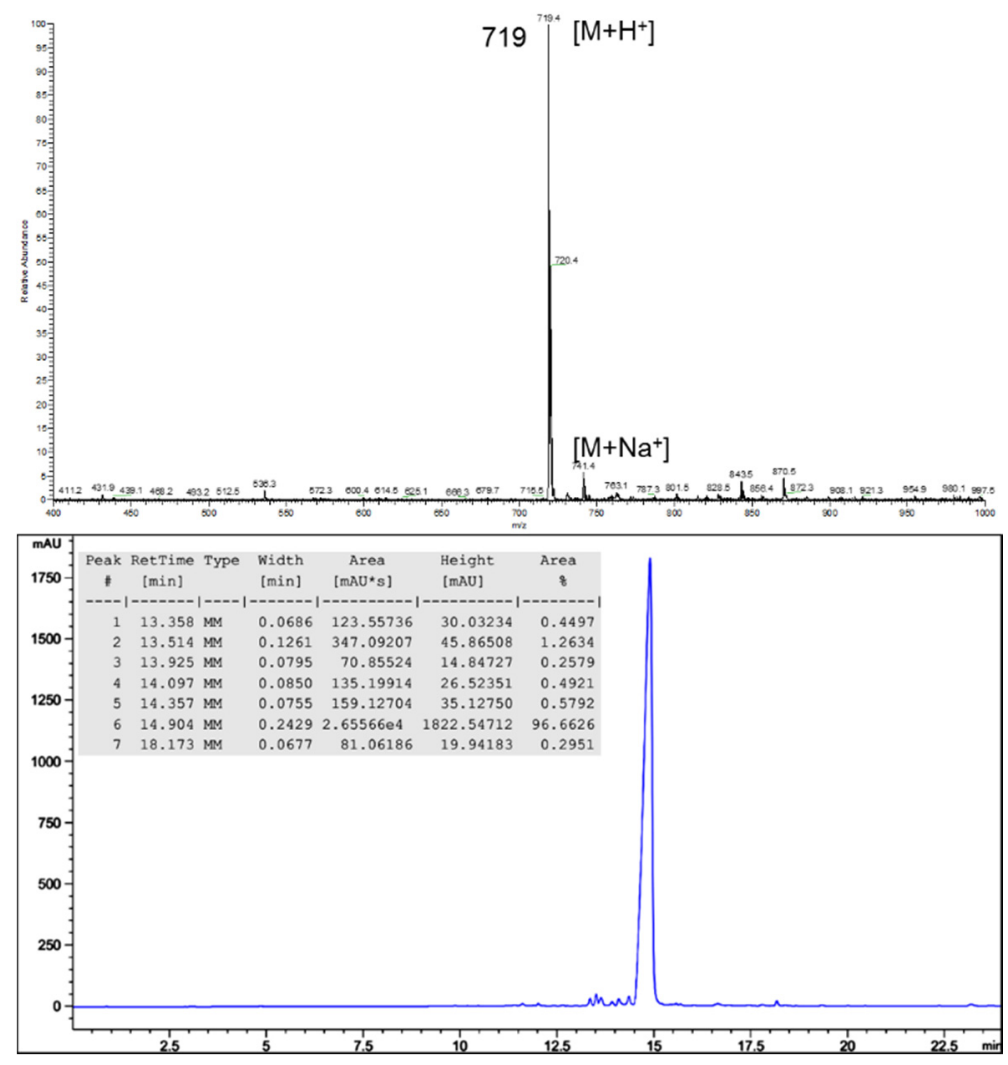

Figure S2. Mass spectrum and analytical HPLC trace of peptide AmpF.
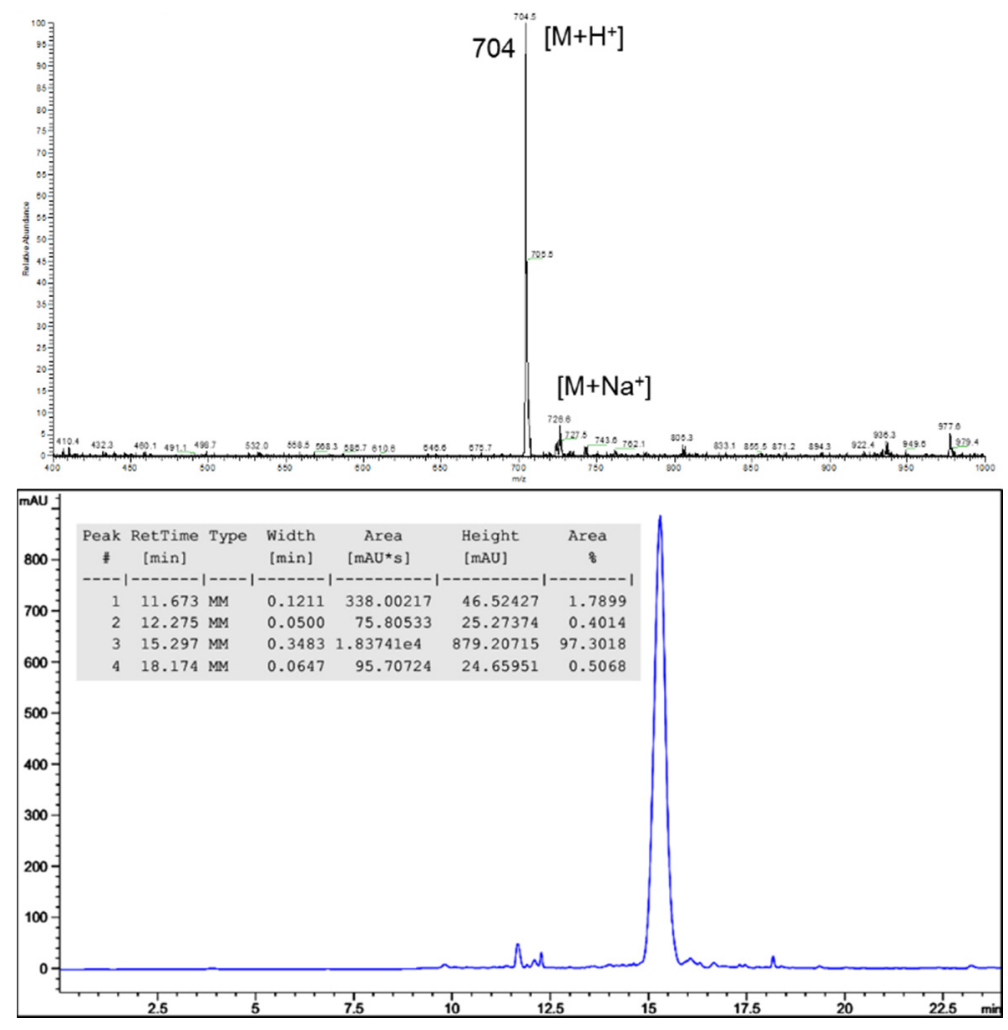

Figure S3. Mass spectrum and analytical HPLC trace of peptide PF. 

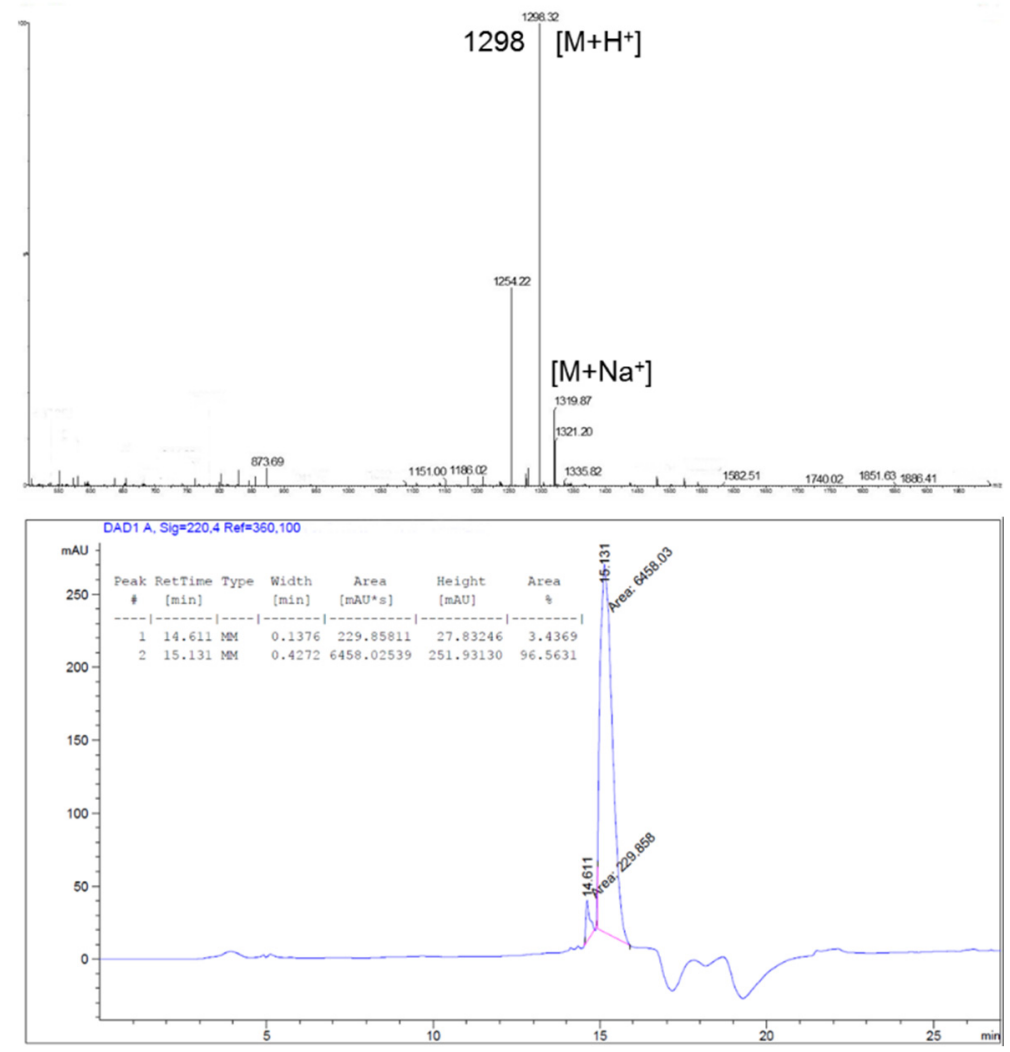

Figure S4. Mass spectrum and analytical HPLC trace of peptide AmpF-C.
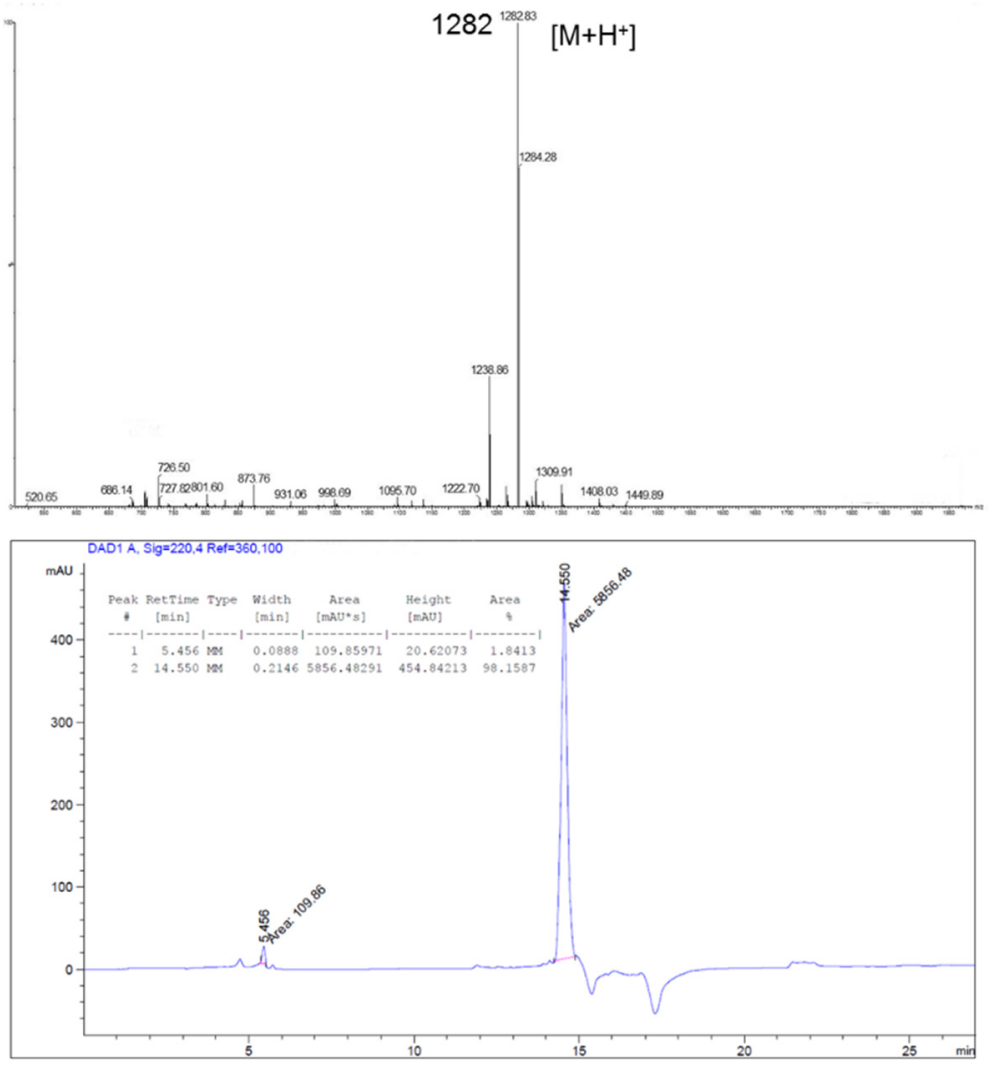

Figure S5. Mass spectrum and analytical HPLC trace of peptide PF-C. 


\section{Circular Dichroism (CD) Spectroscopy}

CD spectra were performed on a Biologic MOS-500 spectrometer using $0.1 \mathrm{~mm}$ quartz slides. Dissolving the lyophilized powder of peptides $\mathbf{A m p F}$ and $\mathbf{P F}$ in basic water mediated by ammonium hydroxide, neutralizing solution $\mathrm{pH}$ to $7.4,7.2,6.5$, and 5.5 by hydrogen chloride, and eventually annealing the solution for thermodynamic equilibration led to the stock solution of peptides AmpF and $\mathbf{P F}$ at various $\mathrm{pH}$ with a concentration of $2 \mathrm{mM}$. CD samples are the stock solution of AmpF, PF, TMAS, and TMRS samples with a concentration of $2 \mathrm{mM}$. CD scans were recorded with a wavelength interval of $1.0 \mathrm{~nm}$ and in the range from 190 to $260 \mathrm{~nm}$.

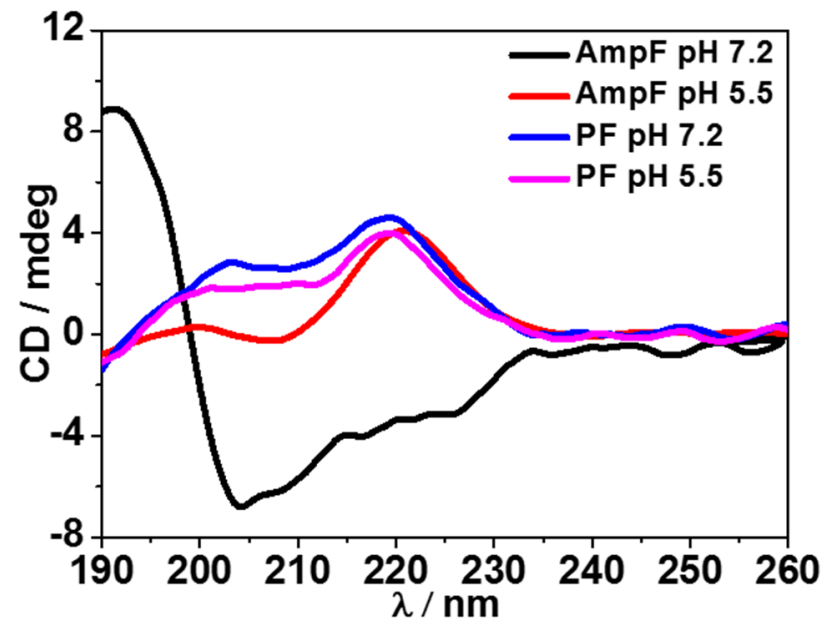

Figure S6. CD spectra of peptides AmpF and PF at pH 7.2 and 5.5.
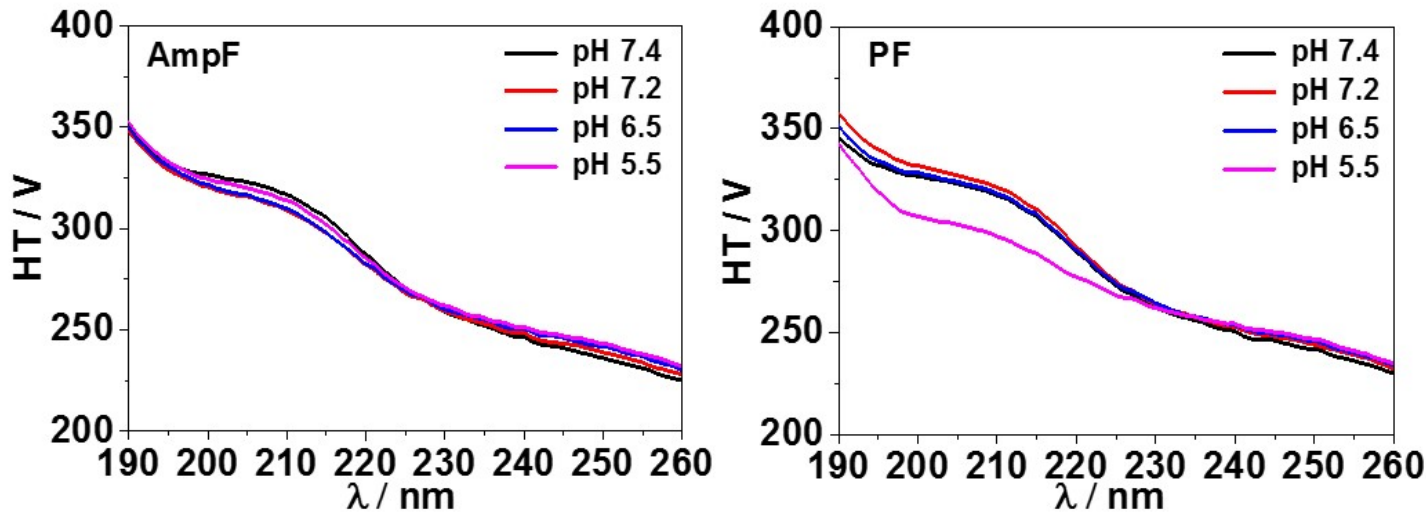

Figure S7. HT signals for CD spectra of peptides AmpF and $\mathbf{P F}$ at various $\mathrm{pH}$. 


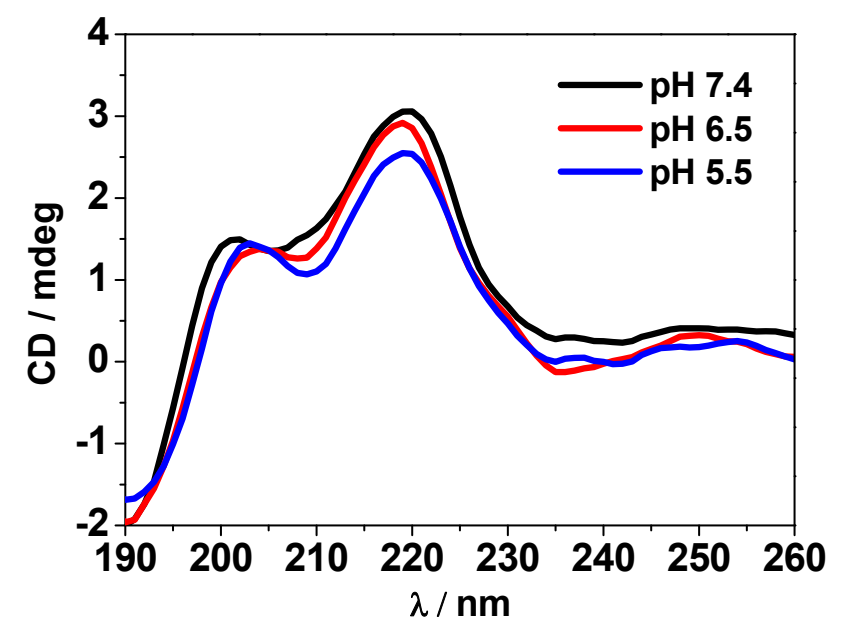

Figure S8. CD spectra of TMRS system at $\mathrm{pH} 7.4,6.5$, and 5.5.
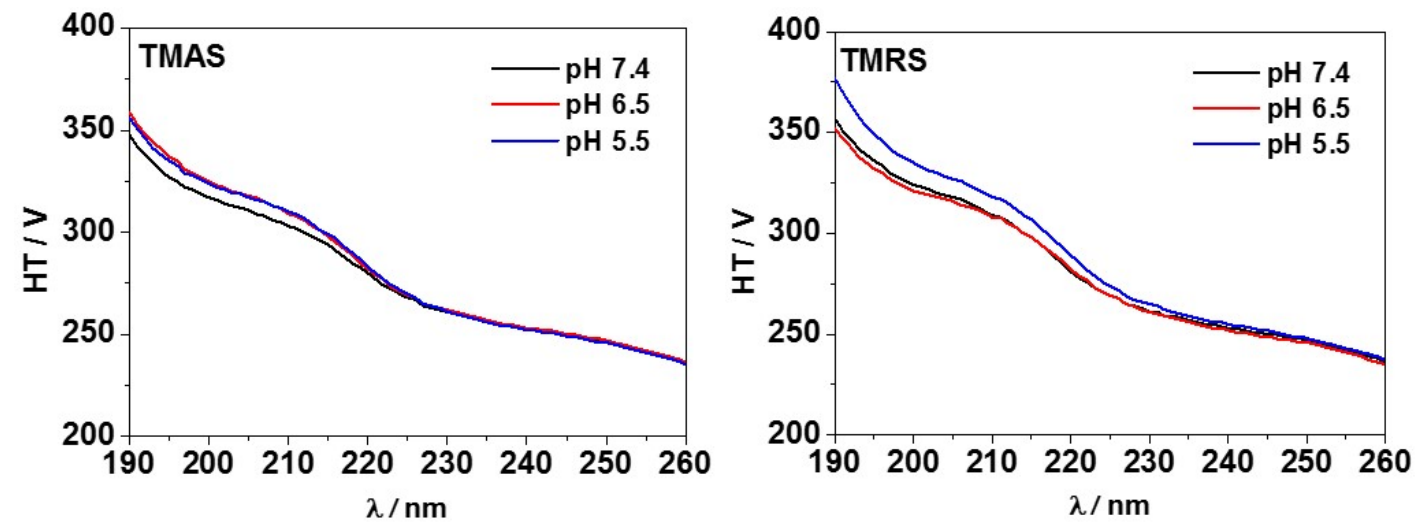

Figure S9. HT signals for CD spectra of TMAS and TMRS systems at various $\mathrm{pH}$.

\section{Atomic Force Microscopy (AFM)}

AFM images of AmpF, PF, TMAS, and TMRS were recorded by using Bruker ICON under the tapping mode. AFM samples were prepared by diluting the stock solutions of AmpF, PF, TMAS, or TMRS to a concentration of $500 \mu \mathrm{M}$ and pipetting $10 \mu \mathrm{L}$ on mica surface for $5 \mathrm{~min}$, then removing the retained solution by filter paper. The samples were dried under atmospheric condition prior to measurement. 

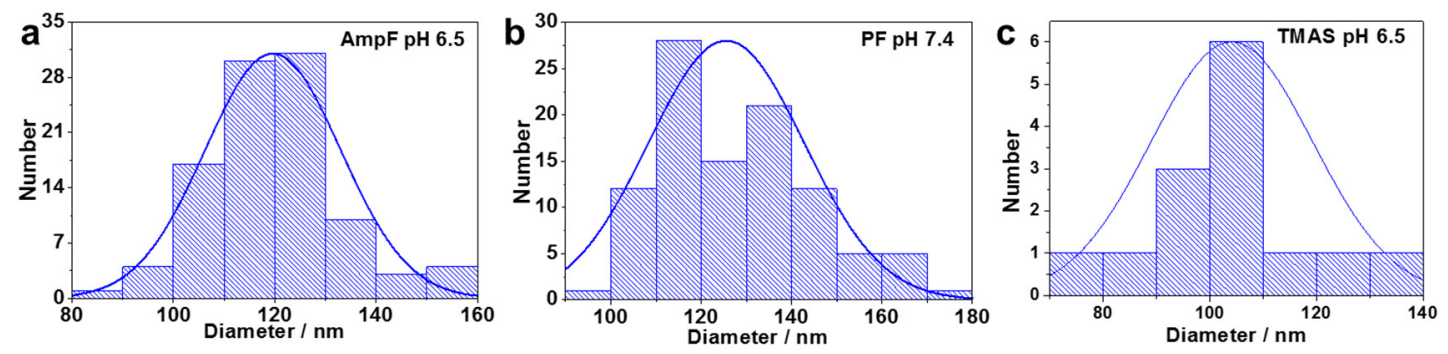

Figure S10. The size distribution of the nanoparticles formed by $\mathbf{A m p F}$ at $\mathrm{pH} 6.5$ (a), PF at $\mathrm{pH} 7.4$ (b), and TMAS at $\mathrm{pH} 6.5$ (c) as shown in Figure 1f, 1b, and $3 \mathrm{~d}$, respectively.
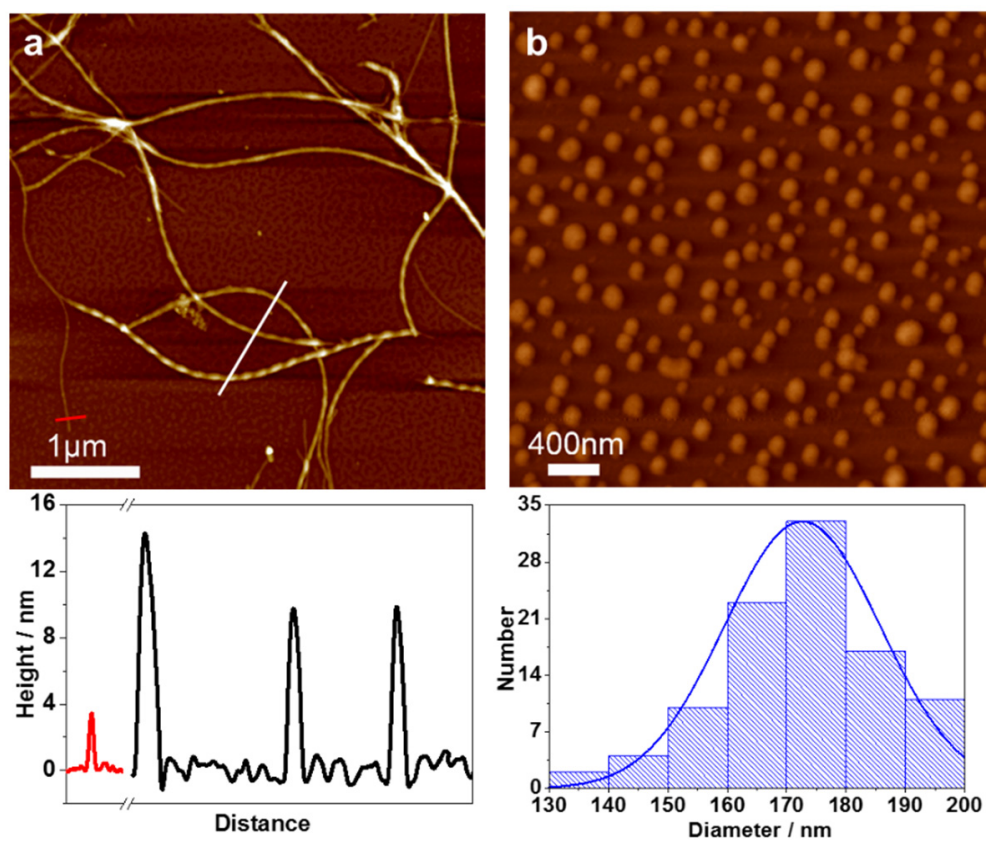

Figure S11. (a) AFM images and the corresponding height profiles of the single fiber and the superhelices consisiting of three or two fibers of AmpF at pH 7.4. (b) AFM image and the size distribution of the nanoparticles formed by $\mathbf{A m p F}$ at $\mathrm{pH}$ 5.5. 

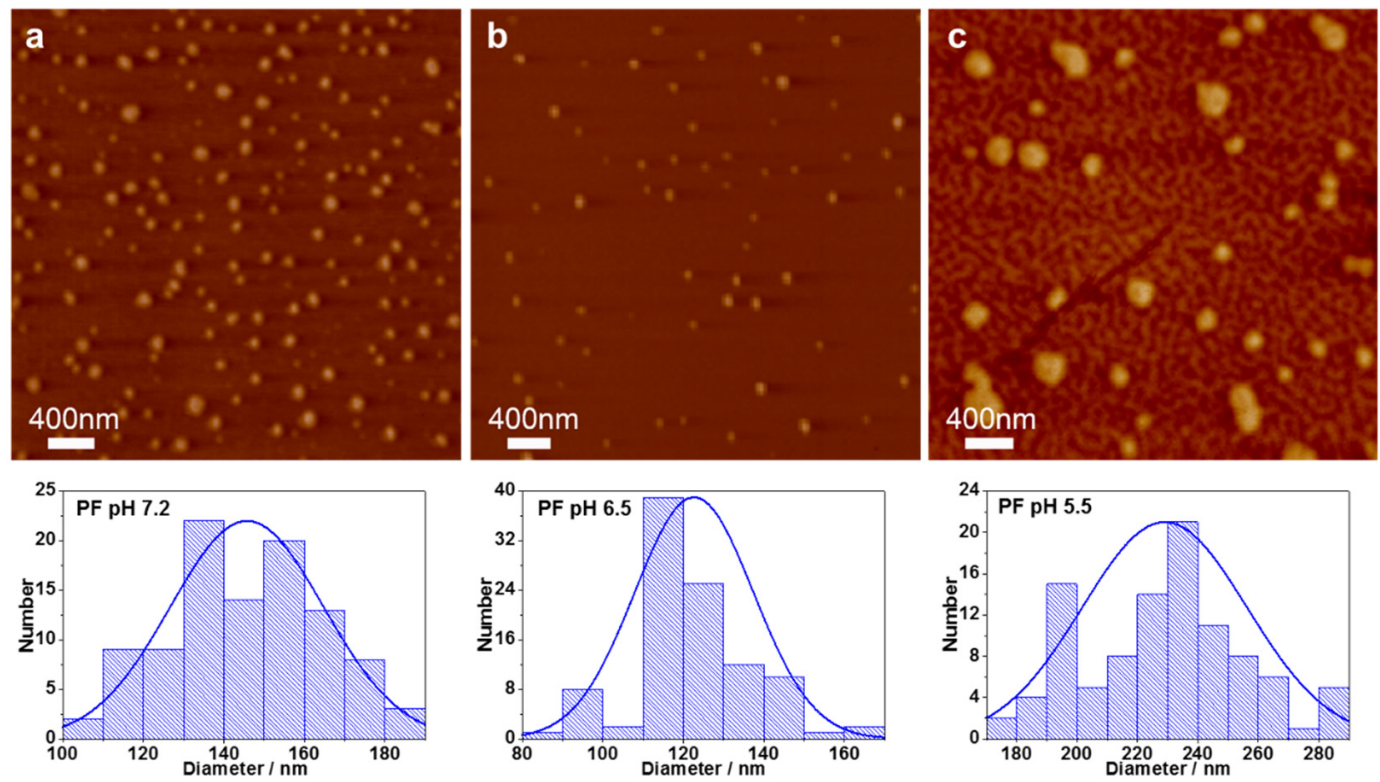

Figure S12. AFM images and the size distribution of the nanoparticles formed by PF at $\mathrm{pH} 7.2(\mathrm{a}), 6.5(\mathrm{~b})$, and 5.5 (c).
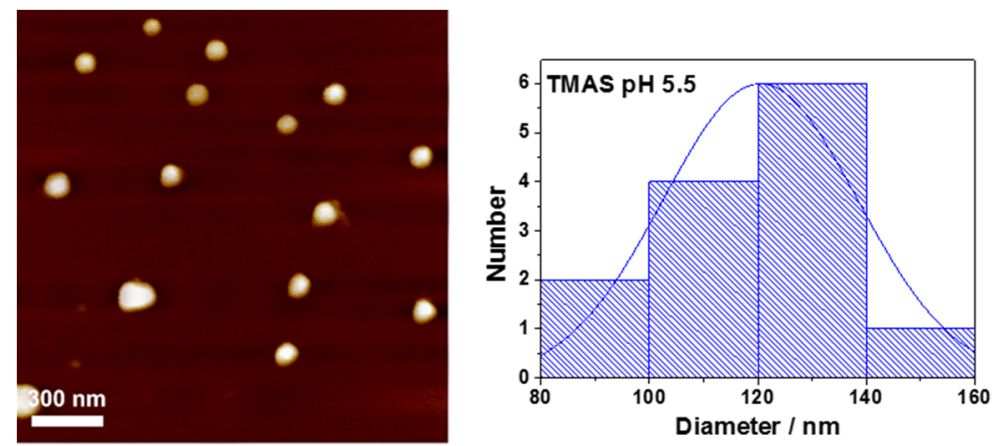

Figure S13. AFM image and the size distribution of the nanoparticles formed by TMAS at $\mathrm{pH}$ 5.5. 

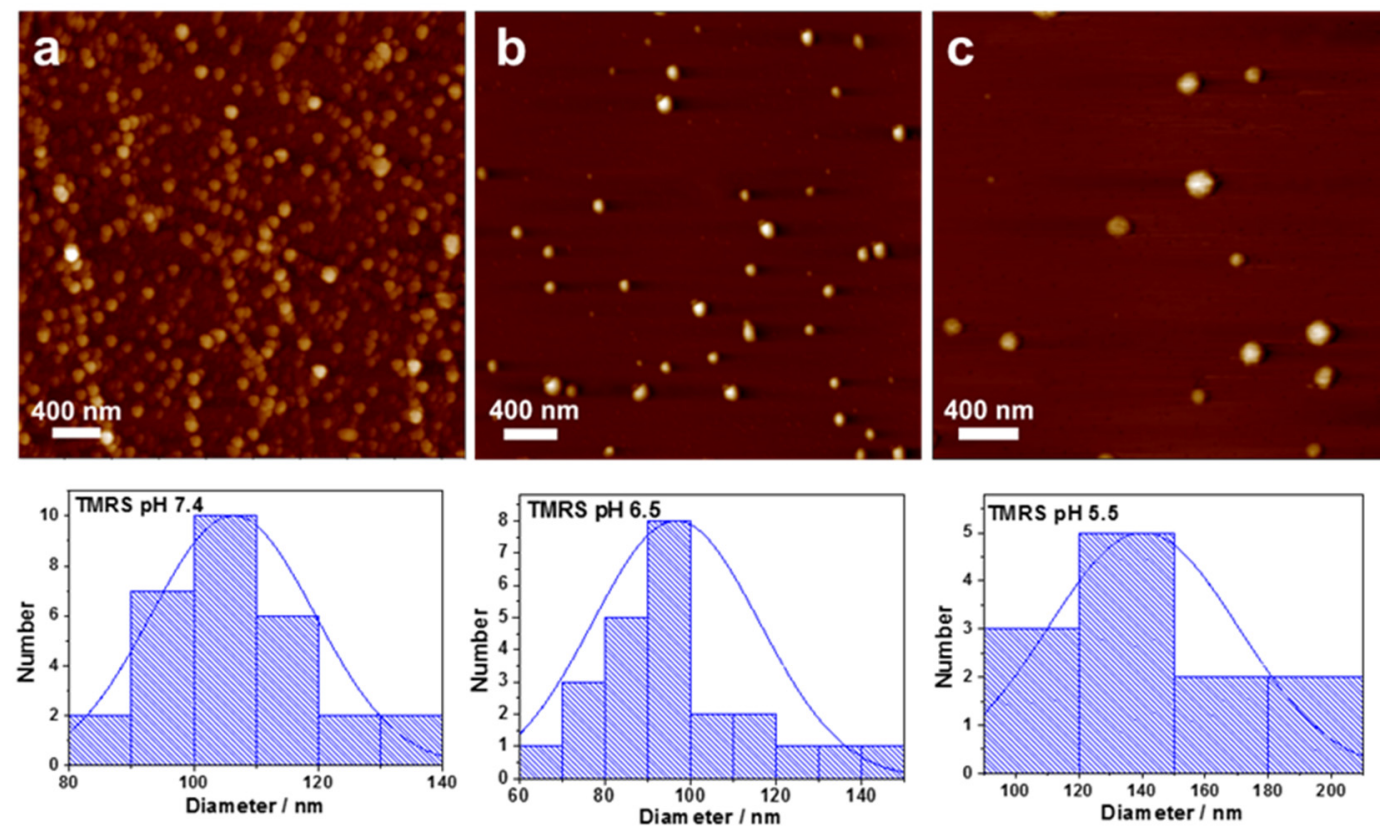

Figure S14. AFM images and the size distribution of the nanoparticles formed by TMRS at $\mathrm{pH} 7.4$ (a), 6.5 (b), and 5.5(c).
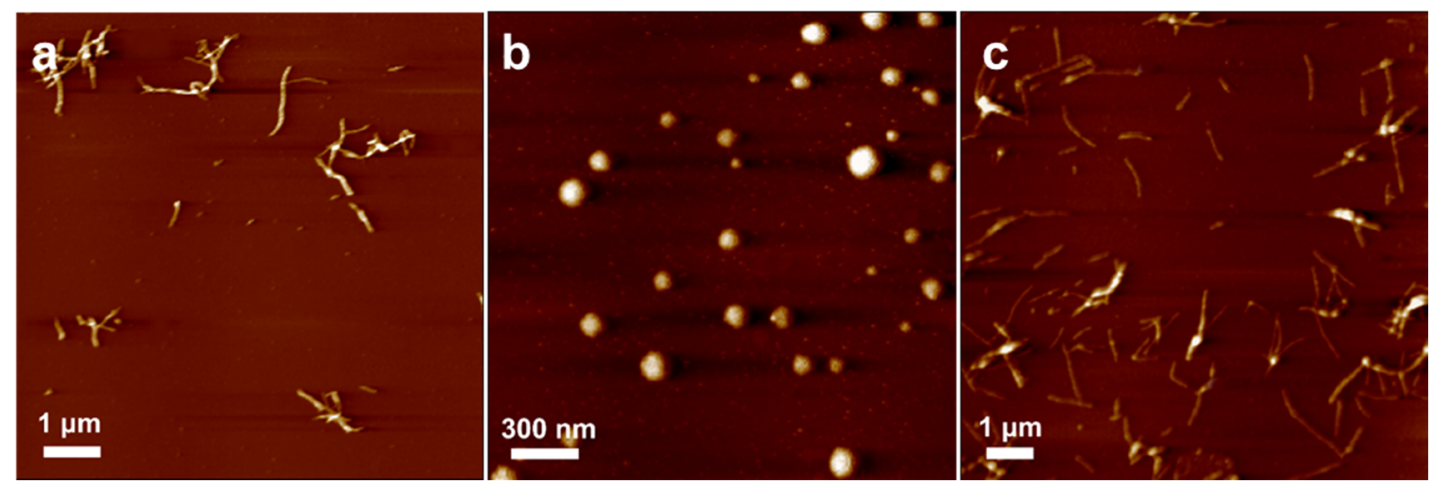

Figure S15. The pH-dependent morphological transition of TMAS as detected by AFM images at pH 7.4 (a), pH 5.5 (b), and pH 7.2 (c), respectively.

\section{Transmission Electron Microscopy (TEM)}

TEM images were recorded by Philips Tecnai G2 20 S-TWIN microscope. TEM samples were prepared by diluting the stock solutions of peptides AmpF and $\mathbf{P F}$ to a concentration of $1 \mathrm{mM}$ and pipetting $3 \mu \mathrm{L}$ on the carbon-coated copper grid. In addition, the TEM samples of TMAS and TMRS systems were prepared by dissolving the lyophilized powder of TMAS or TMRS in 10\% fetal bovines serum (FBS) in PBS mediated by ammonium hydroxide and neutralized to $\mathrm{pH} 7.4$ and 6.5 by hydrogen 
chloride with a concentration of $2 \mathrm{mM}$. The grids were allowed to be dry under the atmosphere and subsequently stained with $6 \mu \mathrm{L}$ of $2 \mathrm{wt} \%$ uranyl acetate for $5 \mathrm{~min}$. The remained stain solution was removed by filter paper and the grids were allowed to be dry under the atmosphere prior to measurement.
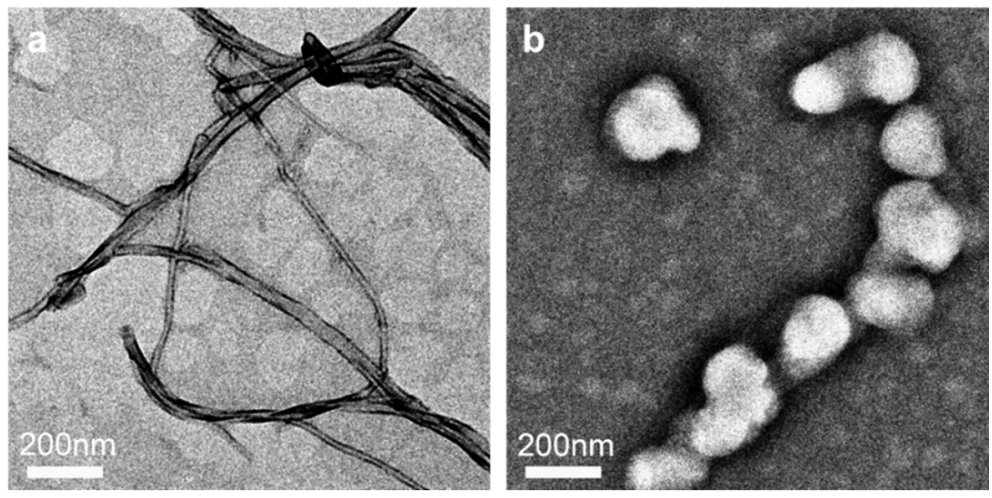

Figure S16. TEM images of peptide AmpF at pH 7.2 (a) and 5.5 (b).
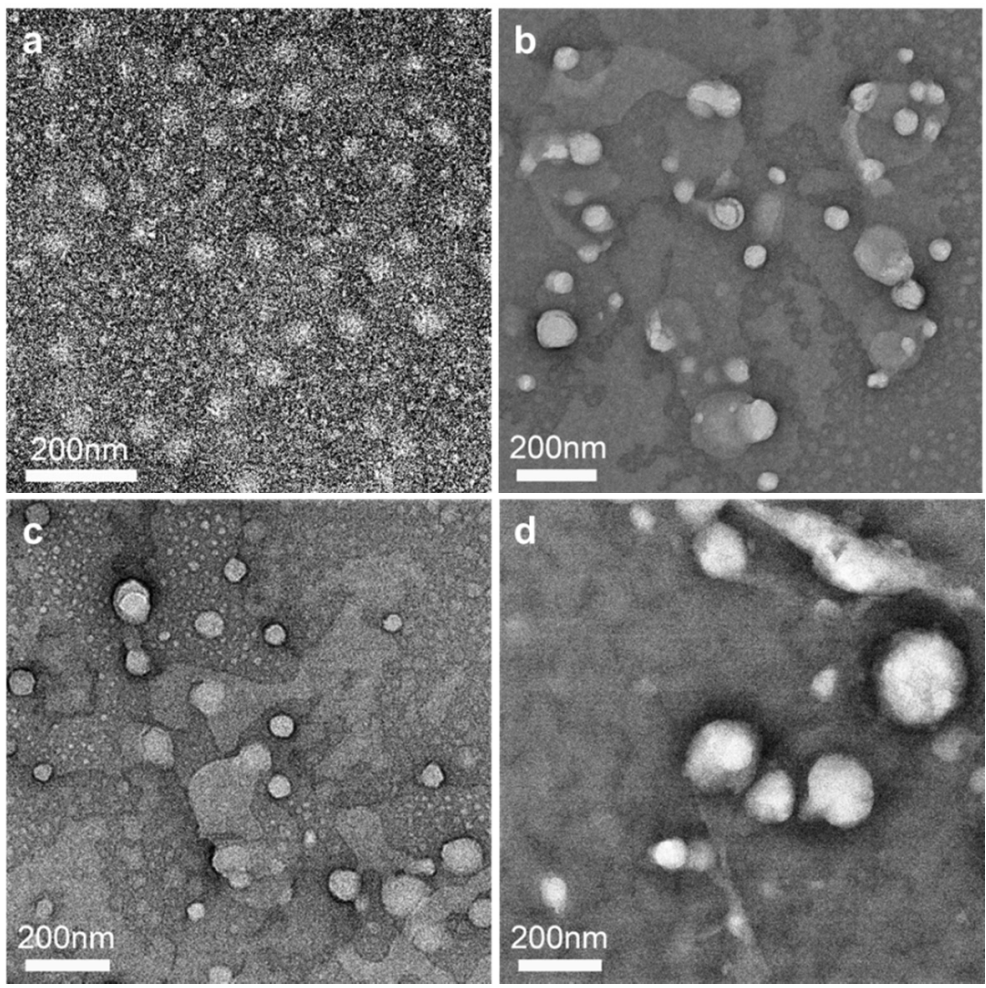

Figure S17. TEM images of peptide PF at pH 7.4 (a), 7.2 (b), 6.5 (c), and 5.5(d). 

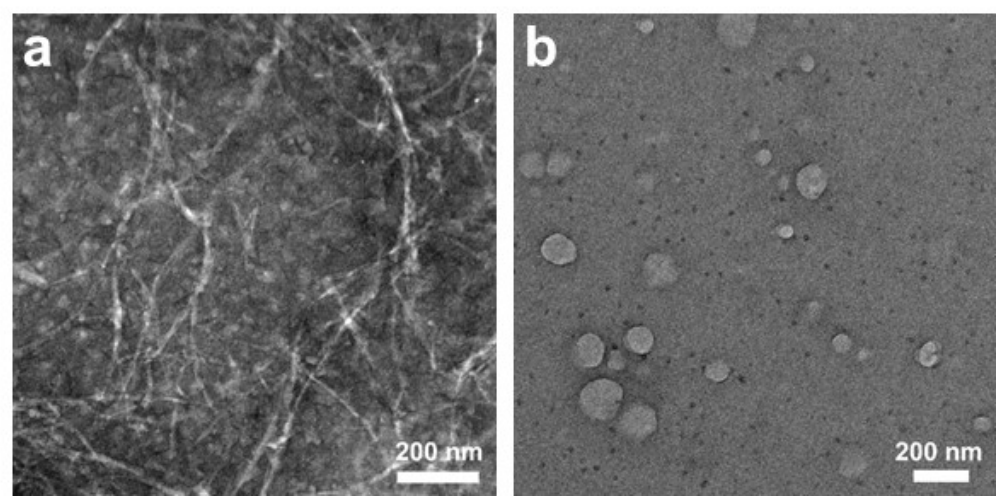

Figure S18. TEM images of TMAS systems in buffer containing 10\% fetal bovine serum (FBS) at $\mathrm{pH} 7.4$ (a) and 6.5 (b), respectively.

\section{Thioflavin T (ThT) Binding Assay}

Fluorescence spectra were collected by Agilent Cary Eclipse fluorescence spectrophotometer using an ultra-micro fluorescence cuvette with an optical path length of $1 \mathrm{~cm}$. The excitation wavelength was $421 \mathrm{~nm}$ and emission was recorded between 450 and $600 \mathrm{~nm}$, with excitation and emission slits of $5 \mathrm{~nm}$. For ThT fluorescence spectra acquisition, the concentration of pentapeptide solutions was $2 \mathrm{mM}$, whereas the concentration of ThT was approximately $19 \mathrm{mM}$ in all the samples. The pentapeptideThT solutions were incubated overnight before measurement. 

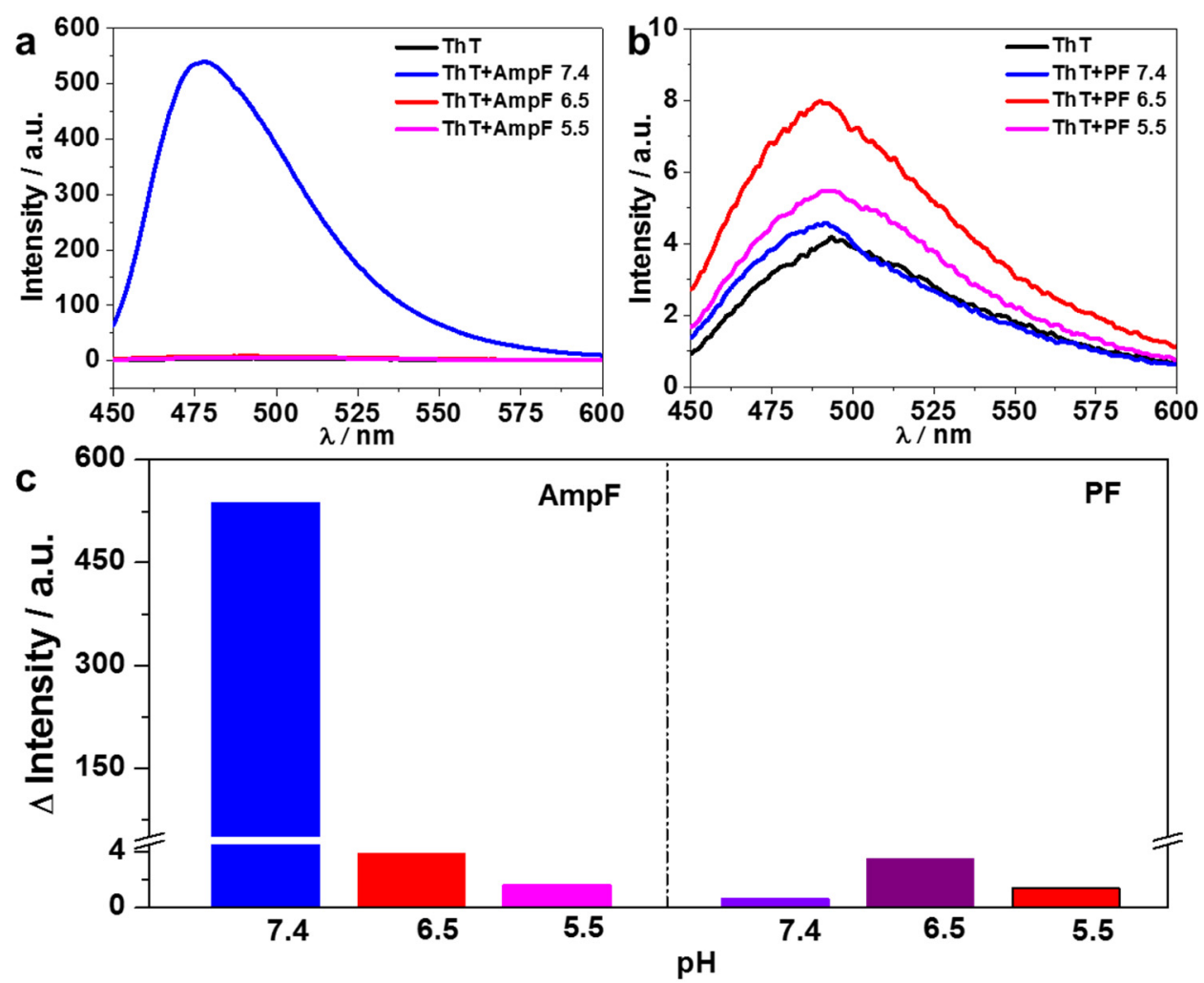

Figure S19. Fluorescence spectra of ThT solutions in the presence of AmpF (a) or PF (b) at $\mathrm{pH} 7.4,6.5$ and 5.5. (c) The differentiated intensity of the maximal emission (@478 nm) of ThT molecular in the presence of AmpF or PF at various pH conditions compared to ThT alone.
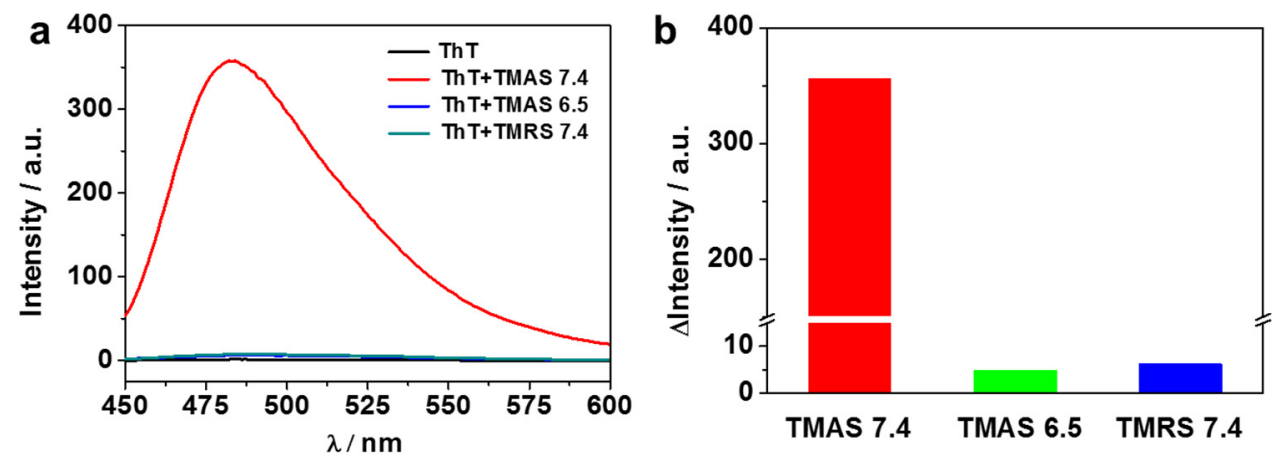

Figure S20. (a) Fluorescence spectra of ThT solutions in the presence of TMAS at $\mathrm{pH}$ 7.4 and 6.5 or TMRS at $\mathrm{pH}$ 7.4. (b) The differentiated intensity of the maximal emission (@483 nm) of ThT molecules in the presence of TMAS or TMRS at various pH conditions compared to ThT alone. 


\section{NMR Studies of Conformer of Xaa-Pro/Amp Amide Bonds}

All NMR spectra were recorded using the stock solutions of peptides PF and AmpF with a concentration of $2 \mathrm{mM}$ in $10 \% \mathrm{D}_{2} \mathrm{O} / 90 \% \mathrm{H}_{2} \mathrm{O}(\mathrm{v} / \mathrm{v})$ at $298 \mathrm{~K}$ by Bruker Avance $600 \mathrm{MHz}$ spectrometer equipped with cryoprobe. The $\mathrm{pH}$ value of the NMR samples was adjusted to $7.4,6.5$, and 5.5 using $100 \mathrm{mM} \mathrm{NaOH}$ and $100 \mathrm{mM} \mathrm{HCl}$. The 1-D proton spectra were recorded using water suppression pulse sequence with recycle delay of $2 \mathrm{~s}$ and 64 scans. $^{[1]} 2$-D proton spectra were recorded in phase-sensitive mode with spectral width of $6500 \mathrm{~Hz}$ for direct and indirect dimensions. The 2-D proton spectra included COSY (cosydfesgpph pulse program), TOCSY (dipsi2esgpph pulse program) with mixing time of $150 \mathrm{~ms}$, and ROESY (roesyesgpph pulse program) with mixing time of $200 \mathrm{~ms}^{[2]}$ The 2-D proton spectra were recorded with 2048 data points in F2, 200 increments in F1 and 40 scans. The TOCSY and ROESY spectra were recorded with 120 scans for peptide AmpF at pH 6.5 due to the relative lower concentration. ${ }^{3} J_{\mathrm{HN}-\mathrm{H}}$ coupling constants were recorded from 1-D proton spectra.

We assigned the sequential resonance signals of both peptides based on the combination of COSY, TOCSY, and ROESY spectra. We estimated the cis- and trans-conformer of the Xaa-Pro amide bonds within peptide PF (F1F2P3F4F5) based on the TOCSY and ROE coupling signals between the protons at $\mathrm{C} \alpha$ of $\mathrm{F} 2$ residue and those at $\mathrm{C} \alpha$ or $\mathrm{C} \delta$ of P3, respectively. ${ }^{[3]}$ In contrast, the ROE coupling signals between the protons at $\mathrm{C} \alpha$ of F2 residue and those at $\mathrm{C} \alpha$ and $\mathrm{C} \delta$ of Amp3 in peptide AmpF (F1F2Amp3F4F5) were not detectable. However, we observed that the strong ROE coupling signal between the protons at $\mathrm{C} \alpha$ of F2 residue and $\gamma-\mathrm{NH} 2$ of Amp3 for peptide $\mathbf{A m p F}$ at $\mathrm{pH}$ 5.5, indicating formation of trans-conformer of Xaa-Amp amide bonds for peptide AmpF at pH 5.5. In addition, the ${ }^{3} J_{\mathrm{NH}-\alpha}$ coupling constant of peptide AmpF at pH 5.5 was determined as 6.9 , which is corresponding to the coupling constant of proline residues adopting a trans-amide conformer. ${ }^{[4,5]}$ This result confirms formation of transconformer of Xaa-Amp amide bonds for peptide AmpF at pH 5.5. Combining 2-D with 1-D ${ }^{1} \mathrm{H}$ NMR spectra of peptide AmpF implies that peptide AmpF adopts an almost 
quantitative trans-amide conformer at $\mathrm{pH}$ 5.5. Furthermore, at $\mathrm{pH} 7.4$ the coupling signal between the protons at $\mathrm{C} \alpha$ of F2 residue and $\gamma-\mathrm{NH} 2$ of Amp3 for peptide AmpF was not observed, whereas ${ }^{1} \mathrm{H}$ NMR of peptide AmpF showed one type of amide protons at $\mathrm{pH} 7.4$, suggesting only one conformer for the Xaa-Amp amide bonds within peptide AmpF at $\mathrm{pH} 7.4$ contrast to that of peptide $\mathbf{A m p F}$ at $\mathrm{pH}$ 5.5. Considering the distinct conformation of peptide AmpF at pH 7.4 comparing to that at $\mathrm{pH} 5.5$, the single conformer of the Xaa-Amp amide bonds within peptide AmpF at pH 7.4 was assigned to the cis-conformer. These results and considerations also allow us to determine the conformer of the Xaa-Amp amide bonds within peptide AmpF at 6.5 as a mixture of trans- and cis-isomers in a ratio of $69 \%: 31 \%$ based on the integration of the signals in 1-D ${ }^{1} \mathrm{H}$ NMR spectra of peptide AmpF at pH 6.5.

Table S1. Population of the cis- and trans-conformers of peptides PF and AmpF determined by NMR studies in water $\left(10 \% \mathrm{D}_{2} \mathrm{O}\right)$ at $\mathrm{pH} 7.4,6.5$, and 5.5.

\begin{tabular}{ccccc}
\hline & \multicolumn{2}{c}{ PF } & \multicolumn{2}{c}{ AmpF } \\
$\mathrm{pH}$ & $\operatorname{trans} / \%$ & cis / \% & trans / \% & cis / \% \\
\hline 5.5 & $61 \pm 1$ & $39 \pm 1$ & 100 & 0 \\
6.5 & $66 \pm 1$ & $34 \pm 1$ & $69 \pm 2$ & $31 \pm 2$ \\
7.4 & $68 \pm 1$ & $32 \pm 1$ & 0 & 100 \\
\hline
\end{tabular}


Table S2. Chemical shifts and ${ }^{3} J_{\mathrm{HN}-\mathrm{H}}$ coupling constants of protons in the trans- and cis-conformers of peptide PF (F1F2P3F4F5) in water $\left(10 \% \mathrm{D}_{2} \mathrm{O}\right)$ at $\mathrm{pH}$ 7.4. Proton signal of F2 amide bonds was not detectable.

\begin{tabular}{ccc|cc}
\hline & \multicolumn{2}{c|}{ trans } & \multicolumn{2}{c}{ cis } \\
& $(\mathrm{ppm})$ & ${ }^{3} J_{\mathrm{HN}-\mathrm{H}}(\mathrm{Hz})$ & $(\mathrm{ppm})$ & ${ }^{3} J_{\mathrm{HN}-\mathrm{H}}(\mathrm{Hz})$ \\
\hline F2-HN & & & \\
F2-H & 4.59 & & 4.08 & \\
P3- H & 4.09 & & 3.18 & \\
P3- H & 1.91 & & 0.96 & \\
& 1.56 & & 1.32 & \\
P3- H & 1.70 & & 0.81 & \\
& 1.62 & & 3.02 & \\
P3-H & 3.30 & & 2.98 & \\
& 3.20 & & 8.12 & \\
F4-HN & 7.73 & & 7.24 & \\
F4-H & 4.37 & & 7.40 & \\
F5-HN & 7.42 & 7.6 & 4.20 & \\
F5-H & 4.22 & &
\end{tabular}

Table S3. Chemical shifts and ${ }^{3} J_{\mathrm{HN}-\mathrm{H}}$ coupling constants of protons in the trans- and cis-conformers of peptide $\mathbf{P F}$ in water $\left(10 \% \mathrm{D}_{2} \mathrm{O}\right)$ at $\mathrm{pH}$ 6.5. Proton signal of F2 amide bonds was not detectable.

\begin{tabular}{ccc|cc}
\hline & \multicolumn{2}{c|}{ trans } & \multicolumn{2}{c}{ cis } \\
& $(\mathrm{ppm})$ & ${ }^{3} J_{\mathrm{HN}-\mathrm{H}}(\mathrm{Hz})$ & $(\mathrm{ppm})$ & ${ }^{3} J_{\mathrm{HN}-\mathrm{H}}(\mathrm{Hz})$ \\
\hline F2-HN & & & \\
F2-H & 4.60 & & 4.10 & \\
P3-H & 4.10 & & 3.17 & \\
P3-H & 1.92 & & 1.45 & \\
& 1.57 & & 1.95 & \\
P3-H & 1.71 & & 0.79 & \\
& 1.63 & & 3.03 & \\
P3-H & 3.32 & & 2.98 & \\
& 3.20 & & 8.11 & \\
F4-HN & 7.73 & & 7.25 & \\
F4-H & 4.38 & & 7.43 & \\
F5-HN & 7.43 & 7.9 & 4.21 & \\
F5-H & 4.21 & &
\end{tabular}


Table S4. Chemical shifts and ${ }^{3} J_{\mathrm{HN}-\mathrm{H}}$ coupling constants of protons in the trans- and cis-conformers of peptide $\mathbf{P F}$ in water $\left(10 \% \mathrm{D}_{2} \mathrm{O}\right)$ at $\mathrm{pH} 5.5$.

\begin{tabular}{ccc|cc}
\hline & \multicolumn{2}{c|}{ trans } & \multicolumn{2}{c}{ cis } \\
& $(\mathrm{ppm})$ & ${ }^{3} J_{\mathrm{HN}-\mathrm{H}}(\mathrm{Hz})$ & $(\mathrm{ppm})$ & ${ }^{3} J_{\mathrm{HN}-\mathrm{H}}(\mathrm{Hz})$ \\
\hline F2-HN & 8.20 & & 8.45 & \\
F2-H & 4.62 & & 4.12 & \\
P3-H & 4.12 & & 3.15 & \\
P3-H & 1.95 & & 1.44 & \\
& 1.58 & & 0.91 & \\
P3-H & 1.74 & & 1.30 & 7.8 \\
& 1.64 & & 0.72 & \\
P3-H & 3.38 & & 3.03 & 7.5 \\
& 3.20 & & 2.96 & \\
F4-HN & 7.74 & & 8.09 & \\
F4-H & 4.38 & & 7.26 & \\
F5-HN & 7.43 & 8.1 & 4.45 & \\
F5-H & 4.23 & & & \\
\hline
\end{tabular}

Table S5. Chemical shifts and ${ }^{3} J_{\mathrm{HN}-\mathrm{H}}$ coupling constants of protons in the cis- or transconformers of peptide $\mathbf{A m p F}$ in water $\left(10 \% \mathrm{D}_{2} \mathrm{O}\right)$ at $\mathrm{pH} 7.4$ and 5.5, respectively.

\begin{tabular}{|c|c|c|c|c|}
\hline & \multicolumn{2}{|c|}{ pH 5.5} & \multicolumn{2}{|c|}{ pH 7.4} \\
\hline & \multicolumn{2}{|c|}{$\operatorname{trans}$} & \multicolumn{2}{|c|}{ cis } \\
\hline & (ppm) & ${ }^{3} J_{\mathrm{HN}-\mathrm{H}}(\mathrm{Hz})$ & (ppm) & ${ }^{3} J_{\mathrm{HN}-\mathrm{H}}(\mathrm{Hz})$ \\
\hline F2-HN & 8.51 & 6.9 & & \\
\hline F2-H & 4.31 & & 4.25 & \\
\hline P3-H & 3.25 & & 3.41 & \\
\hline \multirow[t]{2}{*}{ P3-H } & 2.53 & & 1.10 & \\
\hline & & & 2.15 & \\
\hline P3-H & 1.57 & & 3.76 & \\
\hline \multirow[t]{2}{*}{ P3-H } & 4.10 & & 1.98 & \\
\hline & & & 2.61 & \\
\hline F4-HN & 8.55 & 7.5 & & \\
\hline F4-H & 4.42 & & 4.35 & \\
\hline F5-HN & 7.59 & 7.8 & 7.54 & 8.2 \\
\hline F5-H & 4.24 & & 4.23 & \\
\hline
\end{tabular}


Table S6. Chemical shifts and ${ }^{3} J_{\mathrm{HN}-\mathrm{H}}$ coupling constants of protons in the trans- and cis-conformers of peptide AmpF in water $\left(10 \% \mathrm{D}_{2} \mathrm{O}\right)$ at $\mathrm{pH} 6.5$.

\begin{tabular}{lcccc}
\hline & \multicolumn{2}{c}{ trans } & \multicolumn{2}{c}{ cis } \\
& $(\mathrm{ppm})$ & ${ }^{3} J_{\mathrm{HN}-\mathrm{H}}(\mathrm{Hz})$ & $(\mathrm{ppm})$ & ${ }^{3} J_{\mathrm{HN}-\mathrm{H}}(\mathrm{Hz})$ \\
\hline F5-HN & 7.49 & 8.0 & 7.44 & 8.0 \\
F5-H & 4.22 & & 4.24 & \\
\hline
\end{tabular}

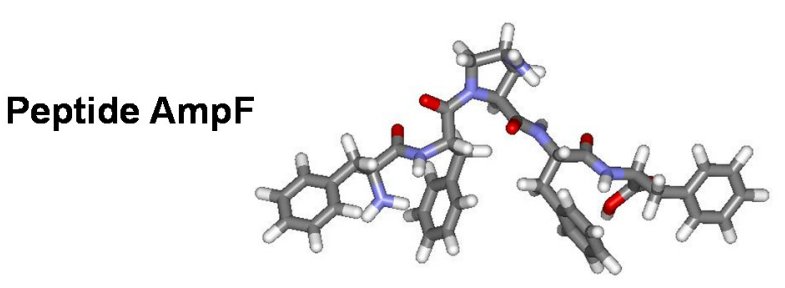

Peptide PF cis-amide

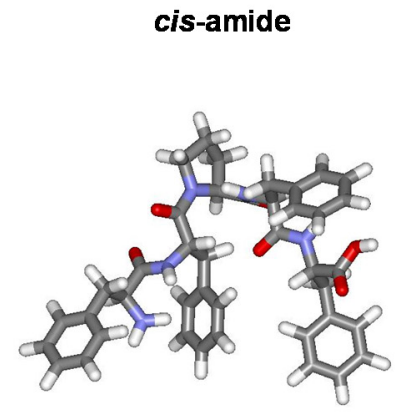

cis-amide

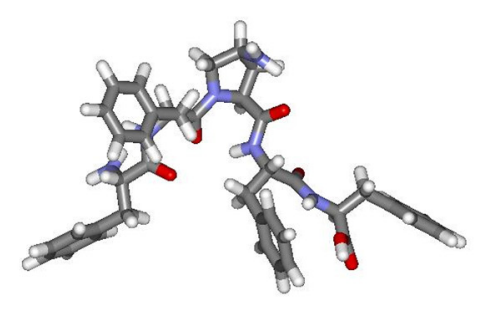

trans-amide

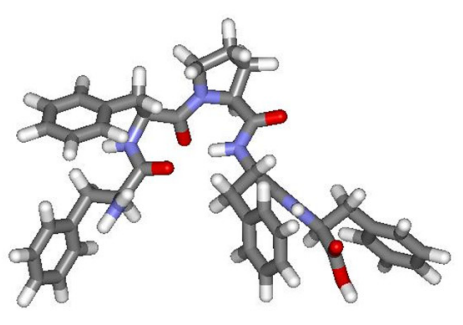

trans-amide

Figure S21. Molecular models of peptides AmpF and PF with a cis- or transconformer for Xaa-Amp/Pro amide bonds obtained from MM2 minimize energy calculation.

Based on the calculated molecular models, peptide AmpF with a cis-amide bond exhibits defined hydrophilic and hydrophobic interfaces occupied by amide bonds as well as 4-amino group of Amp residue and the aromatic groups, respectively. We hypothesized that the segregated interfaces allow cis-AmpF to adopt $\beta$-sheet conformation and assemble into superhelices under neutral condition. In contrast, peptide AmpF with a trans-amide bond as well as peptide PF with either a cis-or transamide bond showed a disordered structure, thus potentially leading to the random coil conformation under neutral condition. 


\section{UV/vis Spectroscopy of TMAS and TMRS}

The UV/vis absorption spectra were recorded on a UV/vis spectrophotometer (Agilent Technologies Cary 60 UV-Vis Model G6860A). UV/vis samples of TMAS and TMRS, were prepared by diluting the stock solutions of TMAS and TMRS, whereas free Ce6 sample was prepared directly by dissolving the Ce6 powder. The concentration of the Ce6 component in TMAS, TMRS, and free Ce6 solutions was maintained as $3 \mu \mathrm{g} / \mathrm{mL}$ for the three UV/vis samples.

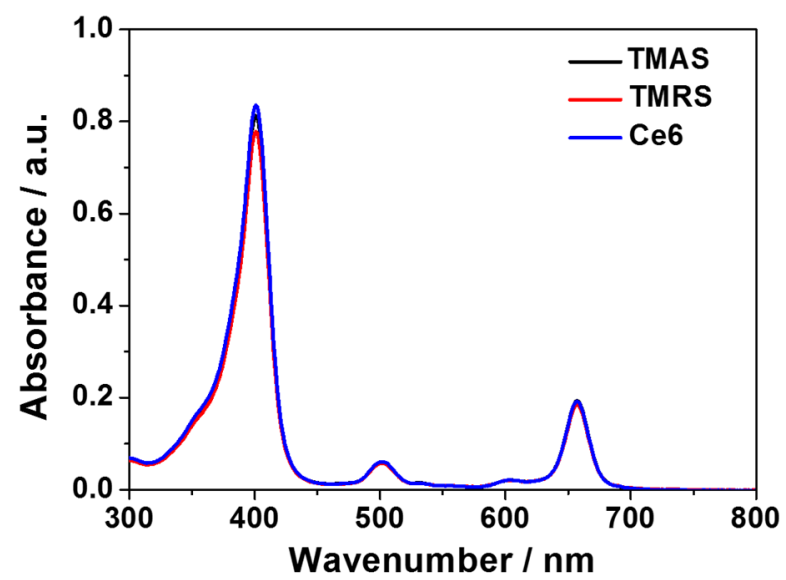

Figure S22. UV/vis absorption spectra of TMAS, TMRS, and Ce6.

\section{In Vitro ROS Generation}

\section{$9.1 \mathrm{UV} /$ vis spectroscopy}

In vitro $\operatorname{ROS}\left({ }^{1} \mathrm{O}_{2}\right)$ generation was detected by using 1, 3-diphenylisobenzofuran (DPBF) as the probe based on its UV/vis absorption intensity at ca. $418 \mathrm{~nm}$ associated with the concentration of ${ }^{1} \mathrm{O}_{2}$ and recorded by a UV/vis spectrometer (Agilent Technologies Cary $60 \mathrm{UV}-\mathrm{Vis}$ Model G6860A). UV/vis samples were prepared by dissolving DPBF in DMSO solution, to which the solution of TMAS, TMRS, or free Ce6 was added, respectively, leading to the samples with DPBF at a concentration of $50 \mu \mathrm{M}$, and a concentration of $0.5 \mathrm{mg} / \mathrm{mL}$ for Ce6 component in TMAS, TMRS, or free Ce6. Meanwhile, the samples containing DPBF, TMAS, TMR, or free Ce6 were prepared with an identical concentration to the corresponding components, for example, $50 \mu \mathrm{M}$ of DPBF solution, $0.5 \mathrm{mg} / \mathrm{mL}$ for the Ce 6 component in TMAS, TMRS, or free Ce6. Al the UV/vis samples were prepared in the dark and were irradiated $(660 \mathrm{~nm}$, 
$0.4 \mathrm{~W} / \mathrm{cm}^{2}$ ) for different time periods ranging from $60 \mathrm{~s}$ to $1200 \mathrm{~s}$. Upon laser irradiation, UV-vis spectra of the samples were measured immediately and the absorption intensity at $413 \mathrm{~nm}$ of DPBF was recorded for plotting.
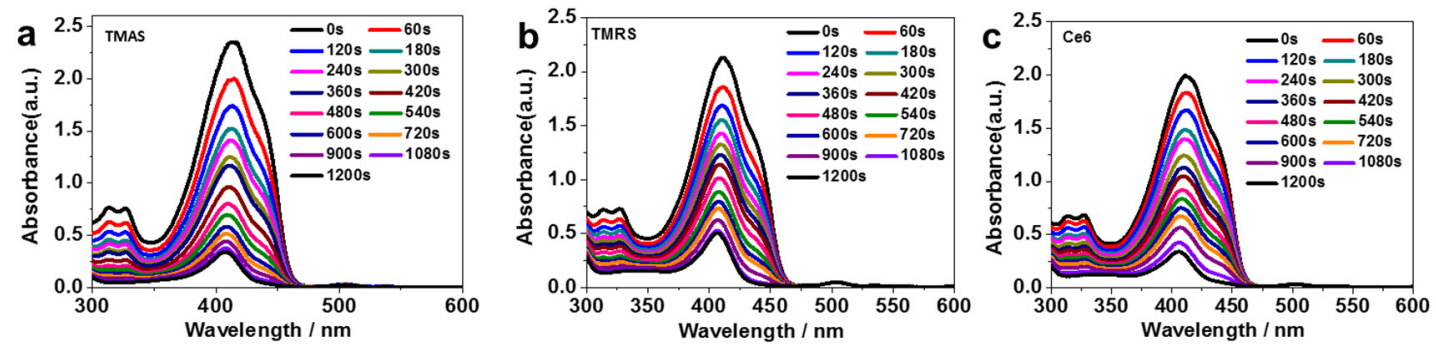

Figure S23. UV/vis absorption spectra of TMAS (a), TMRS (b), and Ce6 (c) upon laser irradiation $(660 \mathrm{~nm})$ for $0 \mathrm{~s}$ to $1200 \mathrm{~s}$, respectively.
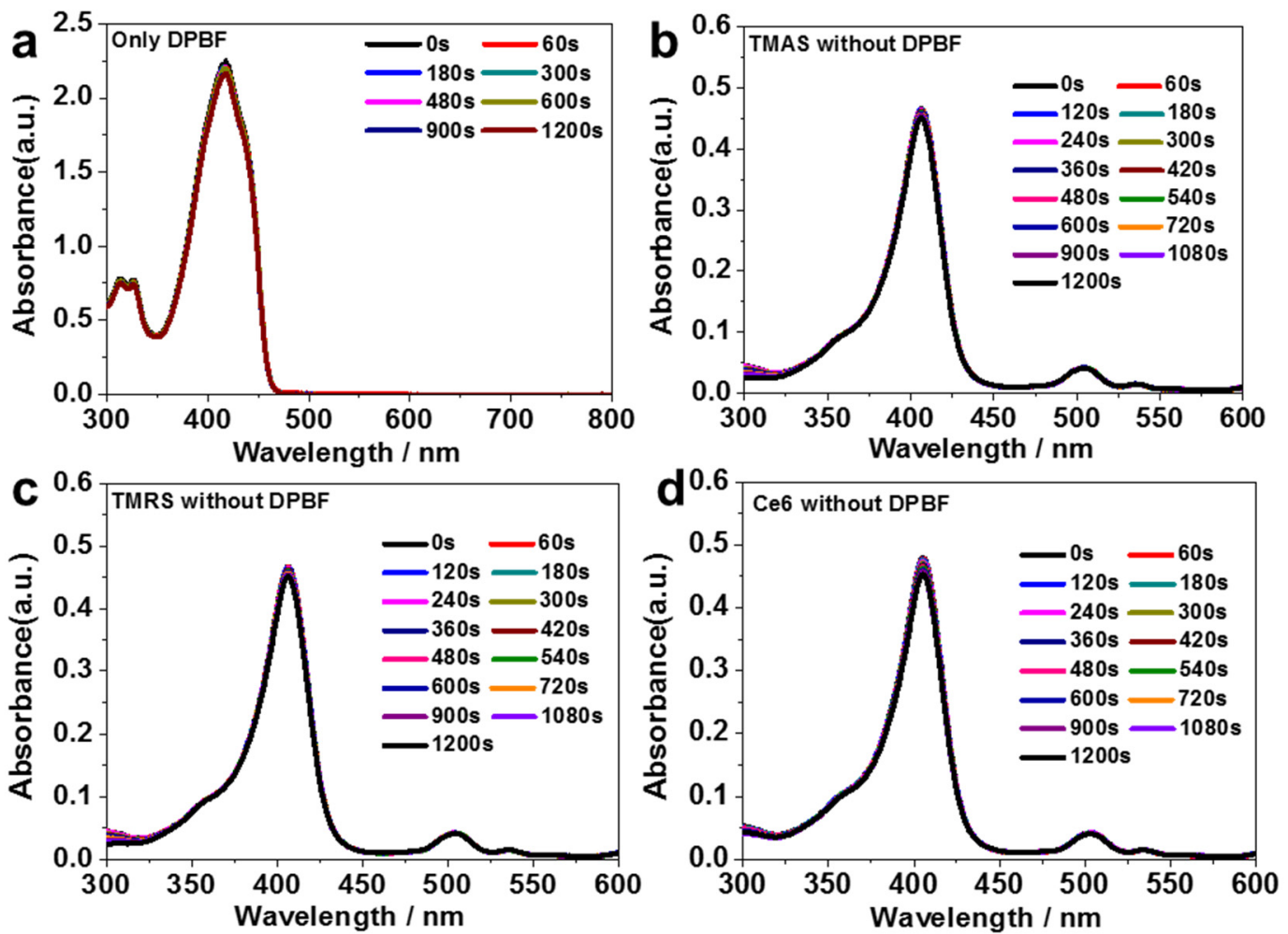

Figure S24. UV/vis absorption spectra of DPBF alone (a), and TMAS (b), TMRS (c), and free Ce6 (d) in the absence of DPBF upon laser irradiation $(660 \mathrm{~nm})$ for $0 \mathrm{~s}$ to $1200 \mathrm{~s}$. 


\subsection{Efficiency of ${ }^{1} \mathrm{O}_{2}$ Generation}

The efficiency for ROS generation of TMAS, TMRS, or free Ce6 was quantified based on the following equations:

$$
\begin{aligned}
\phi_{\text {sample }} & =\phi_{R B} \frac{K_{\text {sample }} A_{R B}}{K_{\text {sample }} A_{R B}} \\
\frac{\phi_{T M A S}}{\phi_{C e 6}} & =\frac{K_{T M A S} A_{C e 6}}{K_{C e 6} A_{T M A S}} \\
\frac{\phi_{T M R S}}{\phi_{C e 6}} & =\frac{K_{T M R S} A_{C e 6}}{K_{C e 6} A_{T M A S}}
\end{aligned}
$$

$\mathrm{A}$ is referred to as the integration of the area in the corresponding $\mathrm{UV} / \mathrm{vis}$ spectra ranging from $400 \mathrm{~nm}$ to $800 \mathrm{~nm}$ of TMAS, TMRS and Ce6 as shown in Figure S22, whereas $\mathrm{K}$ is the slope of the linear fitting functions as shown in Figure S25.
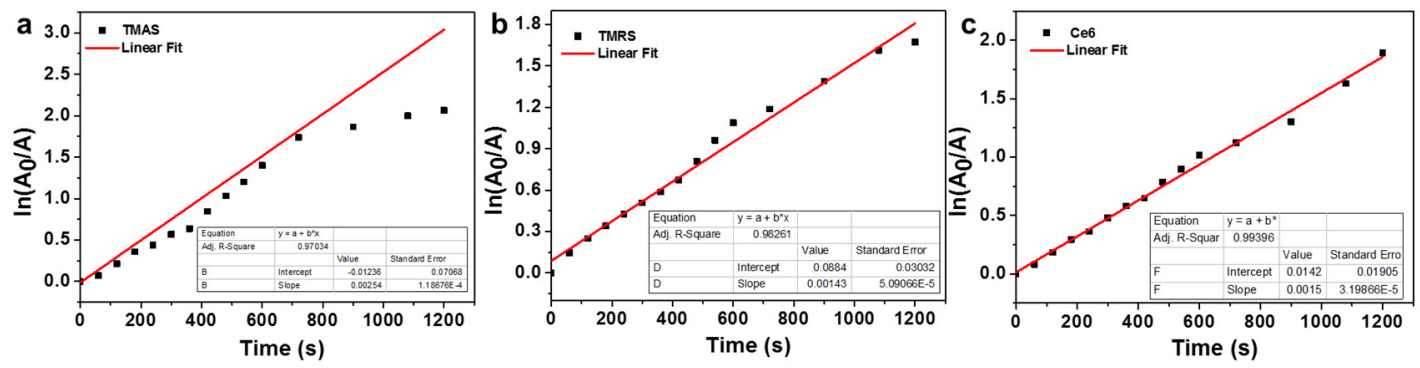

Figure S25. The linear fitting curve of the logarithmically plotted integration of the area in the corresponding UV/vis spectra ranging from $400 \mathrm{~nm}$ to $800 \mathrm{~nm}$ of TMAS, TMRS, and $\mathrm{Ce} 6$ as a funtion of time.

\section{Intracellular ROS Generation}

The intracellular ROS generation was carried out in mouse breast 4T1 tumor cells. The 4T1 cells were seeded on a confocal glass-bottom plate $\left(10^{2} \mathrm{~mm}\right)$ with a density of $1 \times 10^{4}$ cells per well and cultured overnight under the atmosphere of $5 \% \mathrm{CO}_{2}$ at $37^{\circ} \mathrm{C}$. The fresh serum-free Dulbecco's Modified Eagle Medium (DMEM) $(1 \mathrm{~mL})$ containing TMAS, TMRS, or PBS (a constant dose of $1 \mu \mathrm{M}$ for Ce6 component) was added to the cells, which was further incubated at $37{ }^{\circ} \mathrm{C}$ for $4,6,8$, or $10 \mathrm{~h}$. The cells were rinsed with PBS and incubated with 2,7'-dichlorodihydrofluorescein diacetate (DCFH-DA) 
$(10 \mu \mathrm{M})$ in serum-free DMEM $(1 \mathrm{~mL})$ for $30 \mathrm{~min}$. After washing the remained probe by PBS twice, the cells were irradiated by laser $\left(660 \mathrm{~nm}, 0.4 \mathrm{~W} / \mathrm{cm}^{2}, 3 \mathrm{~min}\right)$. The fluorescence imaging of the resulting cells was immediately performed by confocal laser scanning microscope (NIKON A1+).

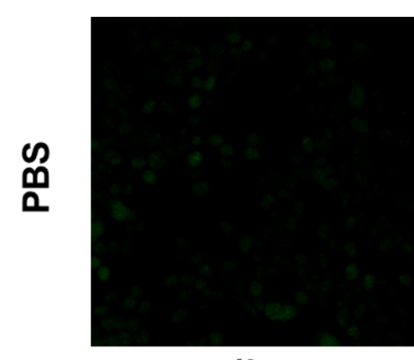

$4 h$

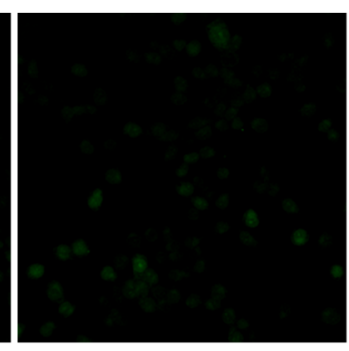

$6 h$

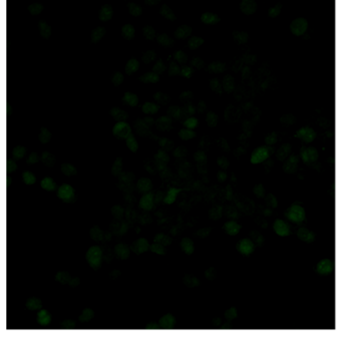

$8 \mathrm{~h}$

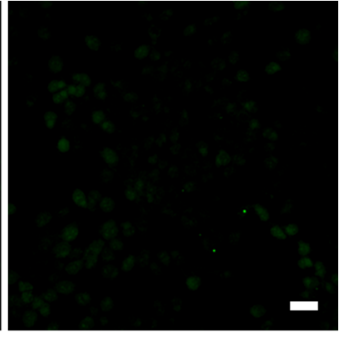

$10 \mathrm{~h}$

Figure S26. Intracellular ROS generation of PBS in breast tumor 4T1 cells at different incubation time points $(4,6,8$, and $10 \mathrm{~h})$ upon laser irradiation $\left(660 \mathrm{~nm}, 0.4 \mathrm{~W} / \mathrm{cm}^{2}\right)$ as detected by confocal laser scanning microscopy (CLSM) using DCFH-DA as a probe. Scale bar: $20 \mu \mathrm{m}$.

\section{In Vitro Cytotoxicity Assay}

In vitro cytotoxicity of TMAS and TMRS was evaluated by MTT assay. 4T1 or 3T3 cells (6000 cells per well) were seeded in 96-well plates with DMEM containing $10 \%$ FBS and 1\% penicillin-streptomycin and cultured overnight. Subsequently, the fresh serum-free medium $(200 \mu \mathrm{L})$ containing TMAS, TMRS, free Ce6 (doses of Ce6 component, 0, 0.075, 0.15, 0.3, 0.45, and $0.6 \mu \mathrm{g} / \mathrm{mL})$, or AmpF (0, 0.625, 1.25, 2.5, 3.75 , and $5 \mu \mathrm{M}$ ) was added to the 96 -well plates and the cells were incubated for another $4 \mathrm{~h}$. After replacing the medium with fresh DMEM $(100 \mu \mathrm{L})$, the cells were exposed to laser ( $660 \mathrm{~nm}, 0.4 \mathrm{~W} / \mathrm{cm}^{2}$ ) for $3 \mathrm{~min}$ in some cases. The cells were incubated overnight and added by MTT solution $(10 \mu \mathrm{L})$ and further cultured for $4 \mathrm{~h}$. Finally, the MTT solution was carefully removed via pipette and DMSO $(100 \mu \mathrm{L})$ was added into the wells. The cells in the plate were measured on a microplate reader (Thermo scientific, USA) via recording the absorption intensity at $492 \mathrm{~nm}$. 


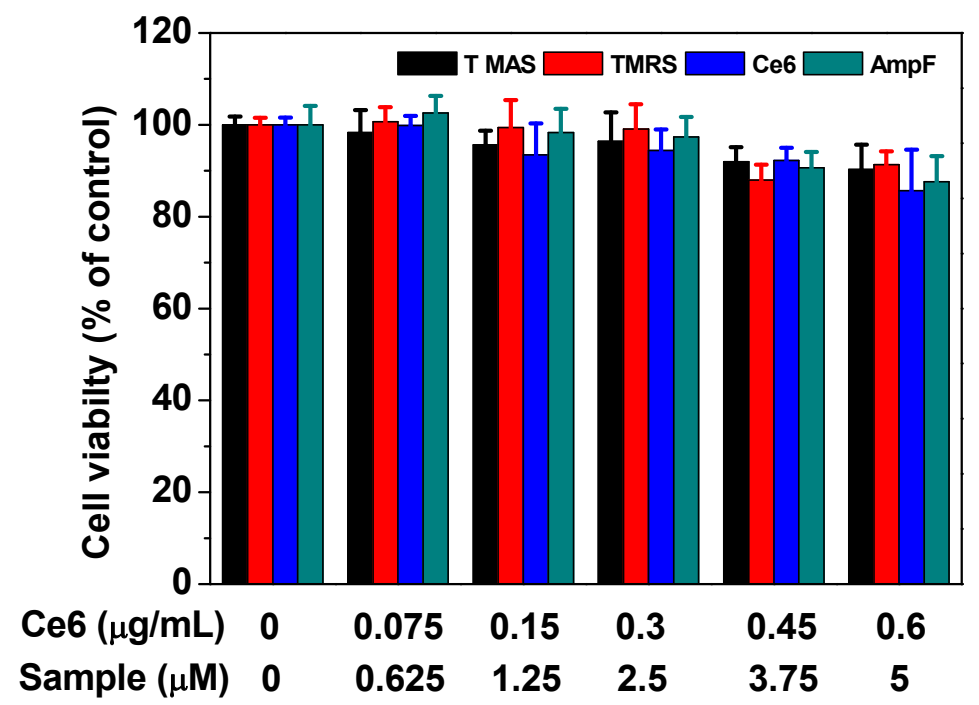

Figure S27.Cell viability of 4T1 cells cultured in the presence of TMAS, TMRS, Ce6, and AmpF without laser irradiation.
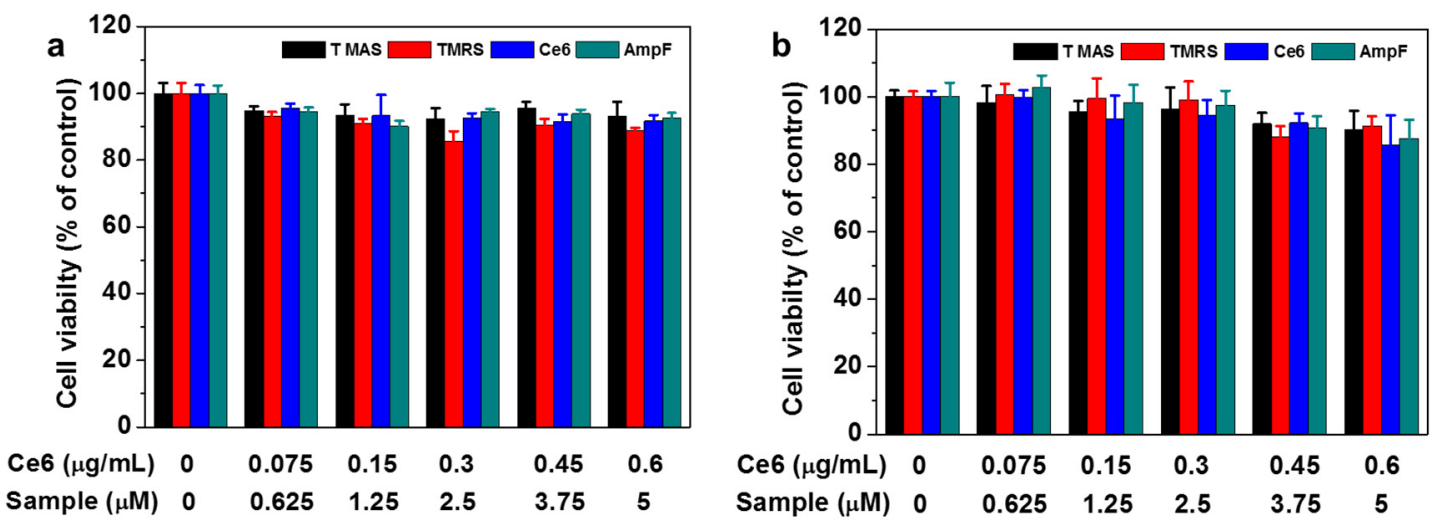

Figure S28. Cell viability of 3T3 cells cultured in the presence of TMAS, TMRS, Ce6, and AmpF without (a) and with (b) laser irradiation. 


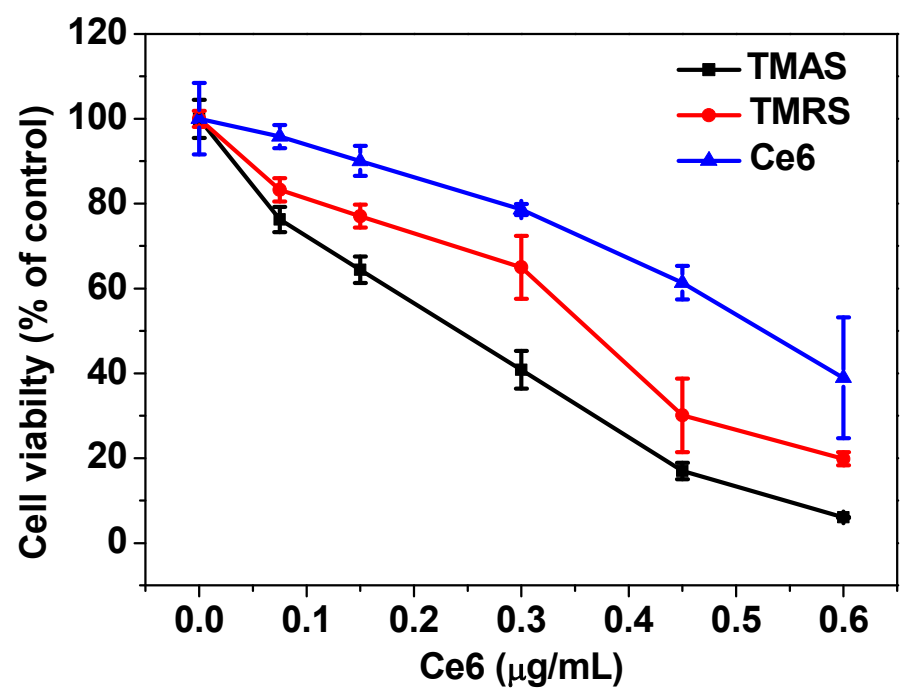

Figure S29. Cell viability of 4T1 cells cultured in the presence of TMAS, TMRS, and free $\mathrm{Ce} 6$ upon laser irradition as a function of the dose of $\mathrm{Ce} 6$ component.

\section{Cellular Uptake Pathway of TMRS and TMAS}

\subsection{Cellular Uptake}

$4 \mathrm{~T} 1$ Cells were seeded on a confocal glass-bottom plate $\left(10^{2} \mathrm{~mm}\right)\left(1.2 \times 10^{5}\right.$ cells per well) containing $1 \mathrm{~mL}$ of DMEM (pH 7.4 or 6.5 ) with $10 \%$ FBS and $1 \%$ penicillinstreptomycin and cultured for $24 \mathrm{~h}$ under the atmosphere of $5 \% \mathrm{CO}_{2}$ at $37{ }^{\circ} \mathrm{C}$. The cells were then washed with PBS and cultured in $1 \mathrm{~mL}$ of the fresh serum-free medium containing TMAS (pH 7.4 or 6.5 ) or TMRS (a dose of $1 \mu \mathrm{M}$ for Ce6 component) for $4,6,8$, or $10 \mathrm{~h}$. Subsequently, the cells were treated with Lysotracker Green (50 nM) for another $30 \mathrm{~min}$. After washing the cells twice with PBS, the cells were fixed with 4\% paraformaldehyde for $20 \mathrm{~min}$ and stained with 4',6-diamidino-2-phenylindole (DAPI) for another $20 \mathrm{~min}$. Finally, the cellular internalization of TMRS and TMAS was imaged by confocal laser scanning microscopy (NIKON A1+). 


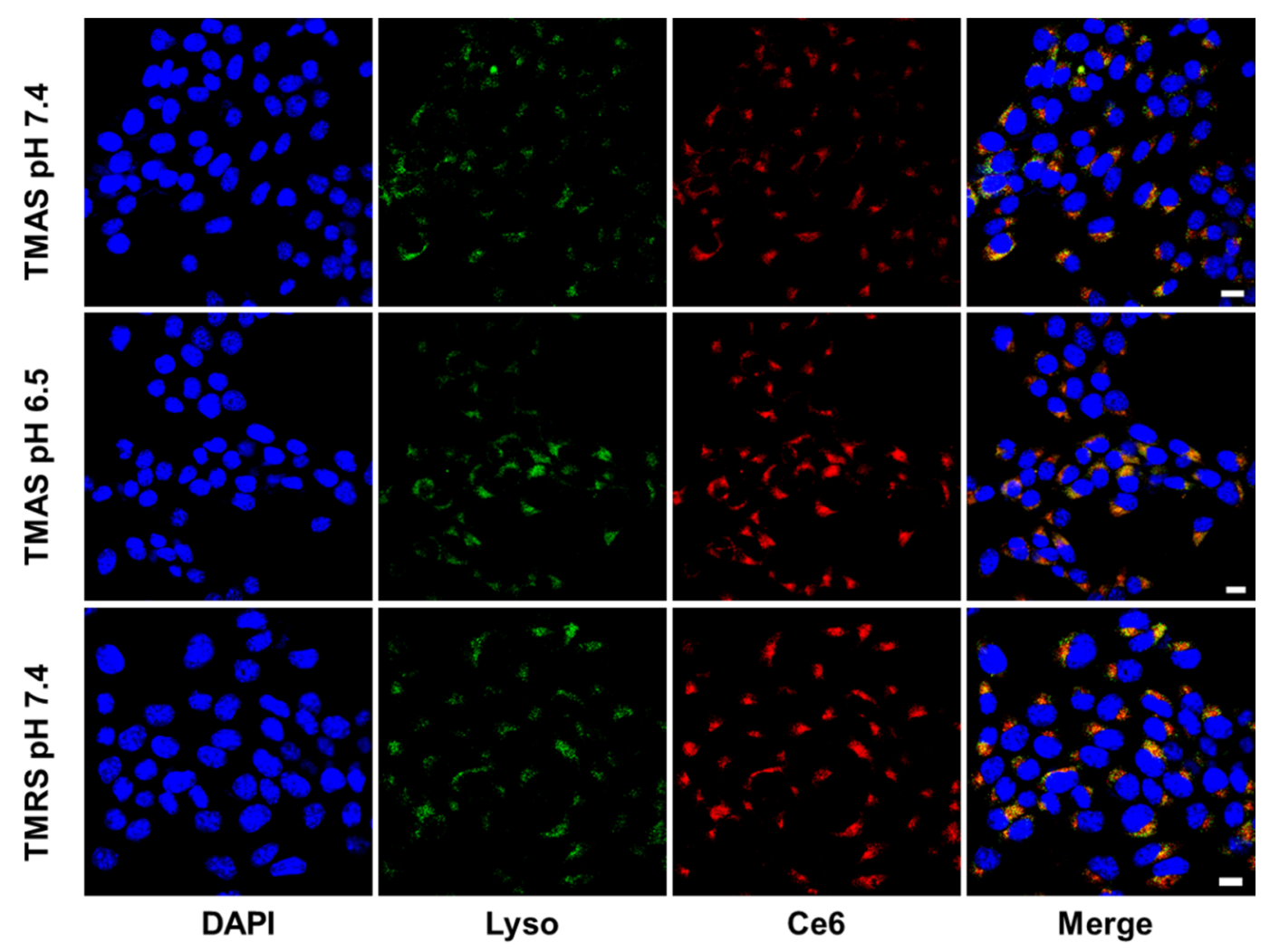

Figure S30. Cellular uptake of TMAS at pH 6.5 and 7.4, and TMRS at pH 7.4 by 4T1 cells after incubating 4 hours detected by CLSM. Scale bar: $20 \mu \mathrm{m}$.

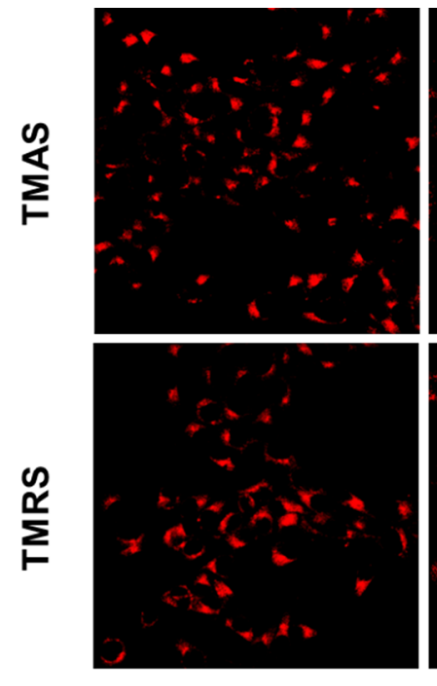

4h
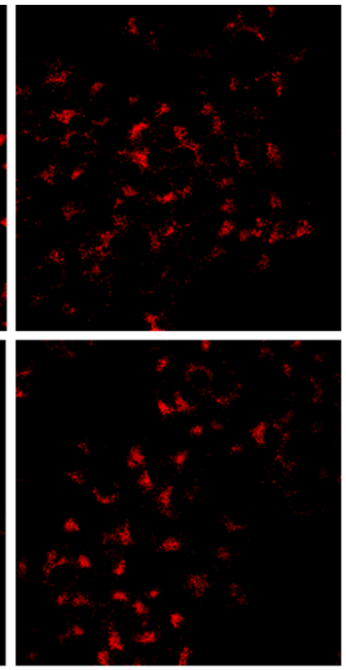

$6 h$
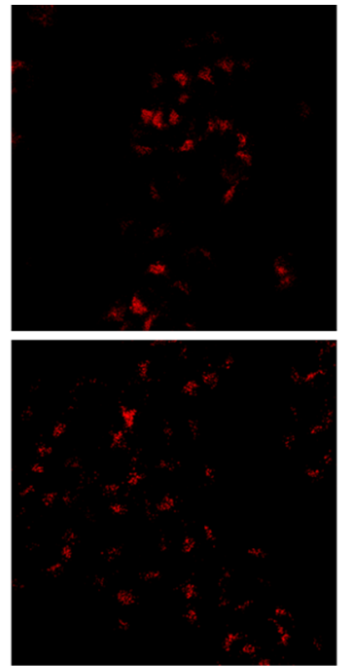

$8 h$
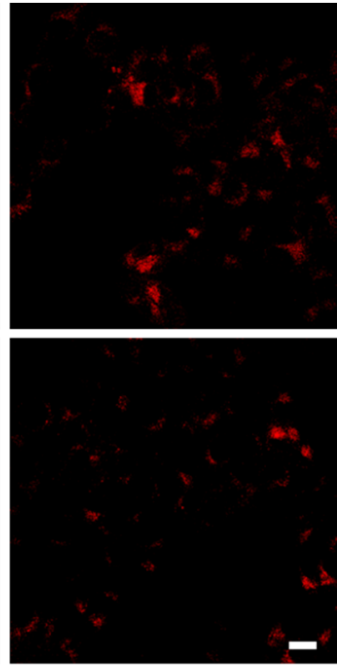

$10 \mathrm{~h}$

Figure S31. Cellular uptake of TMAS and TMRS at different incubation time points $(4,6,8$, and 10 h) by $4 \mathrm{~T} 1$ cells detected by CLSM. Scale bar: $20 \mu \mathrm{m}$. 
The cellular uptake of TMAS and TMRS was also estimated by flow cytometry. 4T1 cells $\left(1.5 \times 10^{5}\right.$ cells per well $)$ seeded in 6-well plates were cultured overnight under $1 \mathrm{~mL}$ of DMEM (pH 7.4 or 6.5) with 10\% FBS and 1\% penicillin-streptomycin under the atmosphere of $5 \% \mathrm{CO}_{2}$ at $37{ }^{\circ} \mathrm{C}$. The cells were washed with PBS and cultured in $1 \mathrm{~mL}$ of fresh serum-free medium containing TMAS ( $\mathrm{pH} 7.4$ or 6.5) or TMRS (a dose of $1 \mu \mathrm{M}$ for Ce 6 component) for $4,6,8$, or $10 \mathrm{~h}$. Then the cells were trypsinized and thoroughly washed with PBS. Re-suspending the incubated cells in $500 \mu \mathrm{L}$ PBS allows for flow cytometric analysis. Fluorescence-activated cell sorting analysis was carried out by BD LSR Fortessa, USA.

Meanwhile, we also characterized the cellular uptake of TMAS and TMRS by mouse fibroblast 3T3 cells under neutral condition by CLSM studies using the identical protocol as 4T1 cells. 3T3 cells were seeded on a confocal glass-bottom plate $\left(10^{2} \mathrm{~mm}\right)$ $\left(1.2 \times 10^{5}\right.$ cells per well) containing $1 \mathrm{~mL}$ of DMEM (pH 7.4 or 6.5$)$ with $10 \%$ FBS and $1 \%$ penicillin-streptomycin and cultured for $24 \mathrm{~h}$ under the atmosphere of $5 \% \mathrm{CO}_{2}$ at $37^{\circ} \mathrm{C}$. The cells were then washed with PBS (pH 7.4) and cultured in $1 \mathrm{~mL}$ of the fresh serum-free medium containing TMAS or TMRS (a dose of $1 \mu \mathrm{M}$ for Ce6 component) for $4 \mathrm{~h}$. Subsequently, the cells were treated with Lysotracker Green $(50 \mathrm{nM})$ for another $30 \mathrm{~min}$. After washing the cells twice with PBS, the cells were fixed with 4\% paraformaldehyde for $20 \mathrm{~min}$ and stained with 4',6-diamidino-2-phenylindole (DAPI) for another 20 min. Finally, the cellular internalization of TMRS and TMAS was imaged by CLSM (NIKON A1+). 


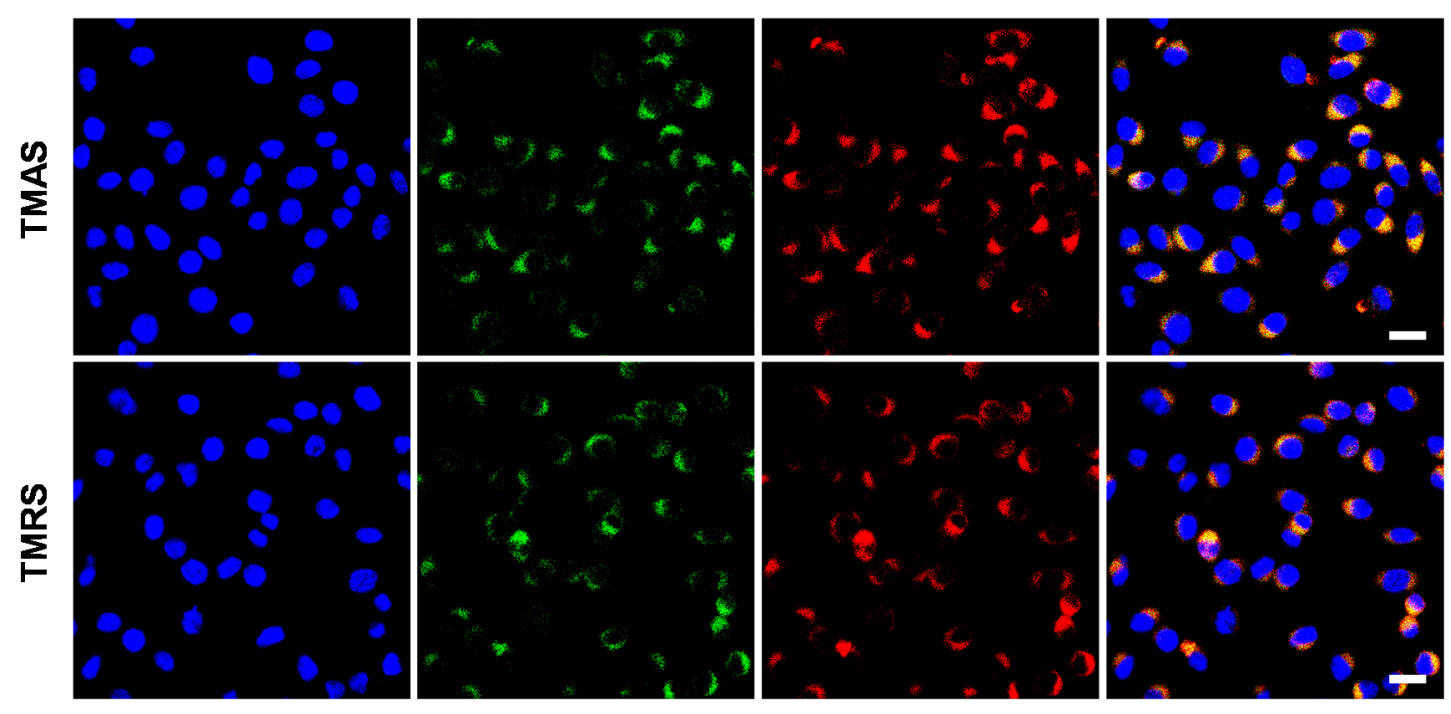

Figure S32. Cellular uptake of TMAS and TMRS by 3 T3 cells after incubating 4 hours at pH 7.4 detected by CLSM. Scale bar: $20 \mu \mathrm{m}$.

\subsection{Endo-/Lysosomal Escape}

$4 \mathrm{~T} 1$ cells were seeded on a confocal glass-bottom plate $\left(10^{2} \mathrm{~mm}\right)\left(1.2 \times 10^{5}\right.$ cells per well) and cultured for $24 \mathrm{~h}$ under the atmosphere of $5 \% \mathrm{CO}_{2}$ at $37^{\circ} \mathrm{C}$. The cells were washed with PBS and cultured in $1 \mathrm{~mL}$ of fresh serum-free medium containing TMRS or TMAS (a dose of $1 \mu \mathrm{M}$ for Ce6 component) for another 4, 6, 8, or $10 \mathrm{~h}$. After washing the cells with PBS, the fresh DMEM with Lysotracker Green (50 nM) was added for another $30 \mathrm{~min}$. Then the cells were fixed with 4\% paraformaldehyde for $20 \mathrm{~min}$ and stained with DAPI for another $20 \mathrm{~min}$. The endo-/lysosomal escape phenomenon was observed by confocal laser scanning microscopy (NIKON A1+). 

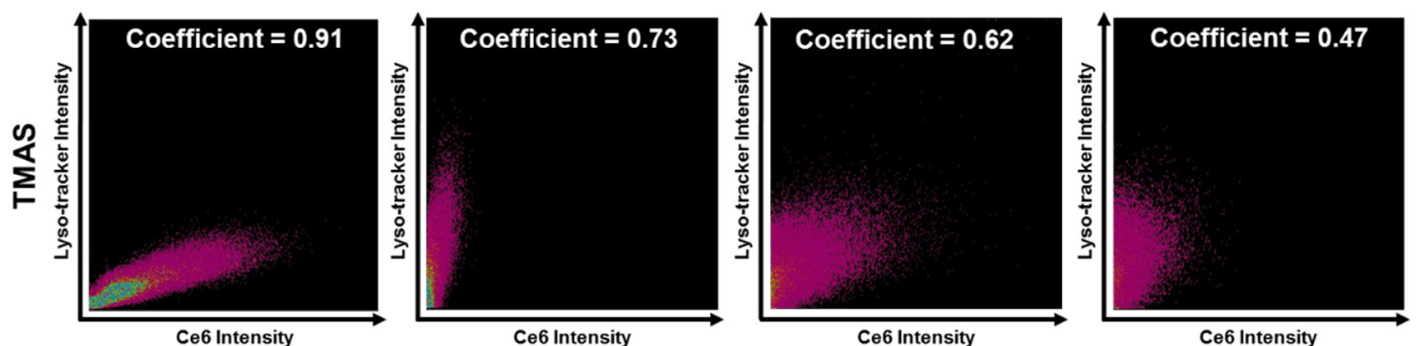

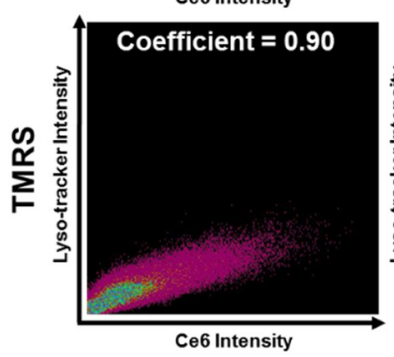

$4 \mathrm{~h}$

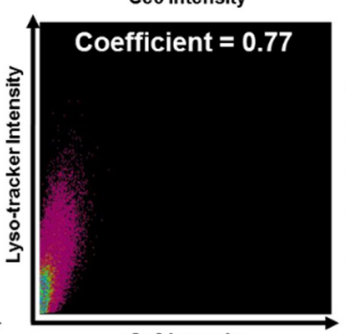

Ce6 Intensity

$6 h$

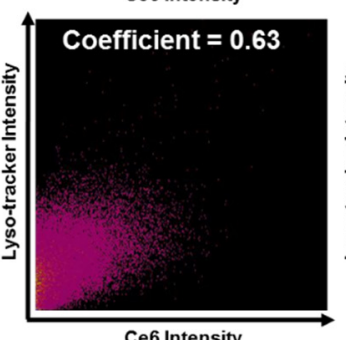

6 Intensity

$8 \mathrm{~h}$

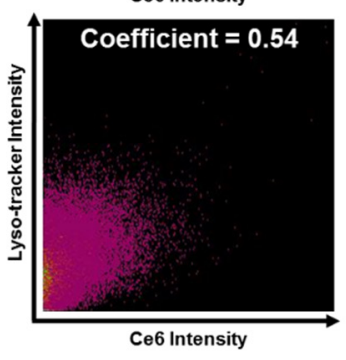

$10 \mathrm{~h}$

Figure S33. The estimated Pearson's correlation coefficient between LysoTracker and Ce6 signals of TMAS and TMRS at different incubation time points (4, 6, 8 and $10 \mathrm{~h})$ as shown in Figure 4d, respectively.

\section{Bio-TEM Studies of Intracellular Morphology}

4T1 cells were incubated in the presence of TMAS or TMRS system (a dose of $1 \mu \mathrm{M}$ for Ce6 component) for $4 \mathrm{~h}$ and $10 \mathrm{~h}$, respectively. After incubation, the cells were trypsinized, thoroughly washed with PBS, and fixed in $2.5 \%$ glutaraldehyde overnight. After removing the fixing solution, the cells were washed with PBS for 15 min (3 times) and further fixed with $1 \%$ citric acid solution for $2 \mathrm{~h}$. Subsequently, the cells was washed with PBS (3 times) and dehydrated with a gradient ethanol-PBS (30 \%, $50 \%$, $70 \%, 80 \%, 90 \%$ and $95 \%$ ) for $15 \mathrm{~min}$ in each case, and treated with $100 \%$ ethanol for $20 \mathrm{~min}$, and finally treated with pure acetone for $20 \mathrm{~min}$. The treated cells were immersed in the EPON 812 resin that was washed with acetone prior to be used. The cells were sectioned in a LEICA EM UC7 ultrathin slicer, and 70-90 nm sections were obtained. Eventually, the sections were stained with lead citrate solution and $50 \%$ ethanol saturated solution of uranyl acetate for $10 \mathrm{~min}$, respectively. The bio-TEM images were recorded by FEI Tecnai Spirit. 


\section{Ex and in Vivo Fluorescence Imaging}

The female 4T1 tumor-bearing mice were obtained by subcutaneously injecting with $4 \mathrm{~T} 1$ cells. When the tumor grew to ca. $150 \mathrm{~mm}^{3}$, the mice were intravenously injected with TMAS, TMRS, or free Ce6 (a dose of $5 \mu \mathrm{M}$ for Ce6 component) and examined by a fluorescence imaging system (Xenogen IVIS Lumina II, USA) for $24 \mathrm{~h}$. Scarifying the mice allows for obtaining the tumors and normal organs (heart, liver, spleen, lung, and kidney), which were immediately estimated under the fluorescence imaging system. All the images were recorded under the constant parameters and scales.

\section{In Vivo Blood Clearance Kinetic Studies}

To monitor the blood clearance rate via fluorescence method, we synthesized peptides AmpF-FAM and PF-FAM by covalently connecting 5-carboxyfluorescein amidite (5FAM) to the N-terminal amine groups of AmpF or PF in solid phase synthesis. A mixture of 5-FAM (8 eq. relative to resin), DIEA (12 eq.) and HATU (7.9 eq.) was added to $\mathrm{NH}_{2}-\mathbf{A m p F}$-resin or $\mathrm{NH}_{2}-\mathbf{A m p F}$-resin and shaken for $4 \mathrm{~h}$. The resins were successively washed by DMF and $\mathrm{CH}_{2} \mathrm{Cl}_{2}$ to remove excess reagents. Cleaving the targeting molecules from resins by the cocktail containing 95\% TFA for $1 \mathrm{~h}$ led to the crude product solution, which was concentrated by rotary evaporation and precipitated by cold diethyl ether. The crude peptides were further purified by RP-HPLC and characterized by ultra-pressure liquid chromatography (UPLC)-MS (Waters SQ Detector 2).

To prepare TMAS-FAM and TMRS-FAM systems, the solution of peptide AmpF, AmpF-FAM, PF, or PF-FAM with a concentration of $10 \mathrm{mM}$ was initially prepared by dissolving the lyophilized peptide powder in basic water mediated by ammonium hydroxide. Mixing the solution of peptides AmpF and AmpF-FAM at a volume ratio of $4: 1$ and adjusting the solution $\mathrm{pH}$ to 7.4 and 6.5 using hydrogen chloride led to the stock solutions of TMAS-FAM under various $\mathrm{pH}$ conditions with a concentration of $2 \mathrm{mM}$, whereas mixing the solutions of peptides PF and PF-FAM gave rise to the 
TMRS-FAM stock solutions via the identical protocol.

The Sprague-Dawley rats $(n=4)$ were intravenously injected with TMAS-FAM or TMRS-FAM at a dose of $10 \mathrm{mg} / \mathrm{kg}$ via tail vein. Blood samples were collected into centrifuge tubes pretreated with EDTA at different time points $(5 \mathrm{~min}, 1 \mathrm{~h}, 2 \mathrm{~h}, 3 \mathrm{~h}, 4 \mathrm{~h}$, $6 \mathrm{~h}, 8 \mathrm{~h}, 12 \mathrm{~h}$, and $24 \mathrm{~h}$ ). Then the blood samples were centrifuged at $3000 \mathrm{rpm}$ for $10 \mathrm{~min}$ to remove the blood cells, thus leading to the plasma fractions. The fluorescence intensity of the blood samples was recorded via Cary Eclipse Fluorescence Spectrophotometer (excitation at $495 \mathrm{~nm}$ and emission at $520 \mathrm{~nm}$ ). The percentage of the injected dose (\%ID) was calculated by comparing the fluorescence intensity of TMAS-FAM or TMRS-FAM retained in blood with the initial fluorescence intensity (5 min). Blank samples from each mouse $(0 \mathrm{~min})$ were collected as the background fluorescence of the plasma.
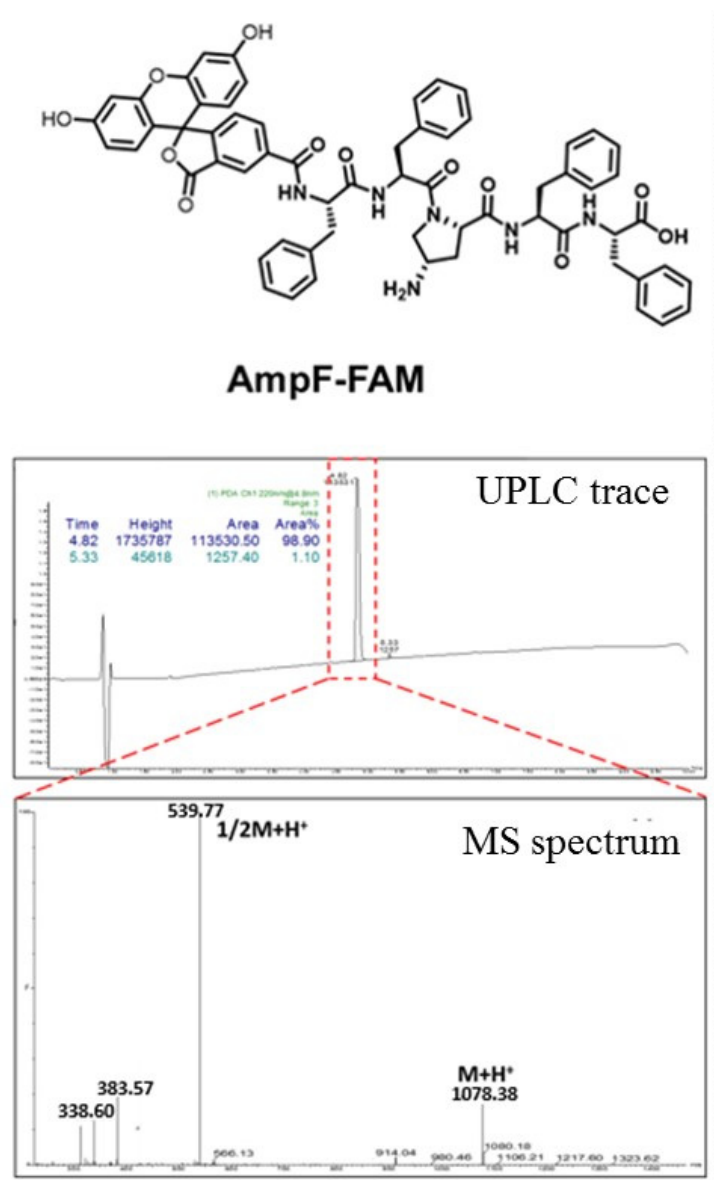

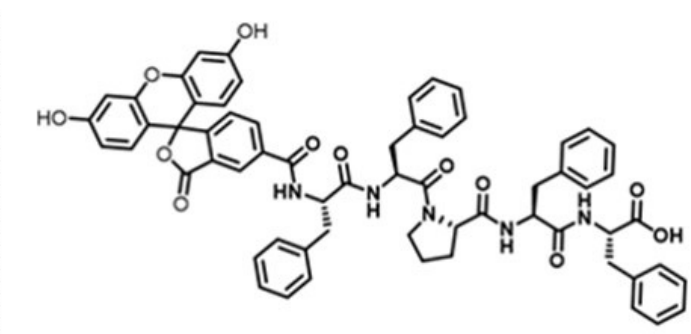

PF-FAM

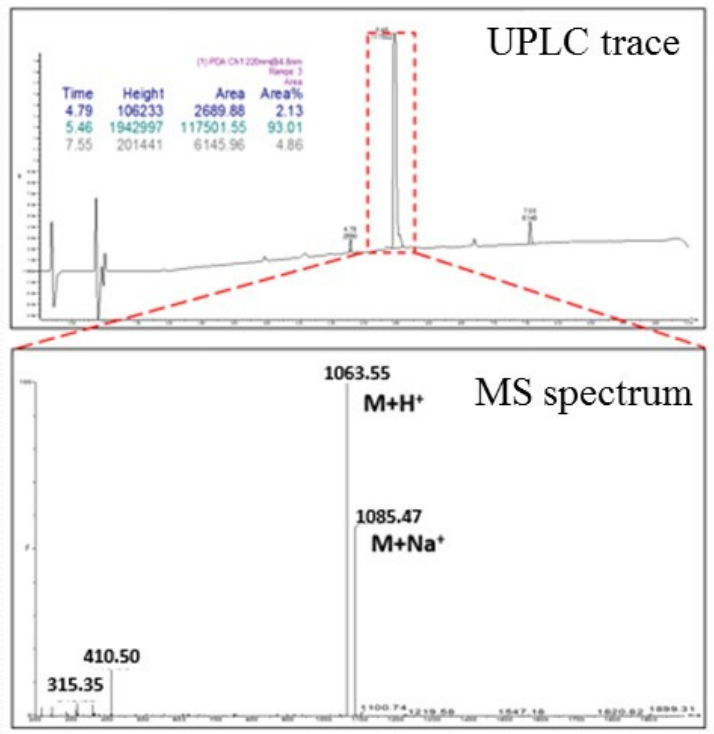

Figure S34. Chemical structure of peptide AmpF-FAM and PF-FAM and their corresponding UPLC traces and mass spectra. 


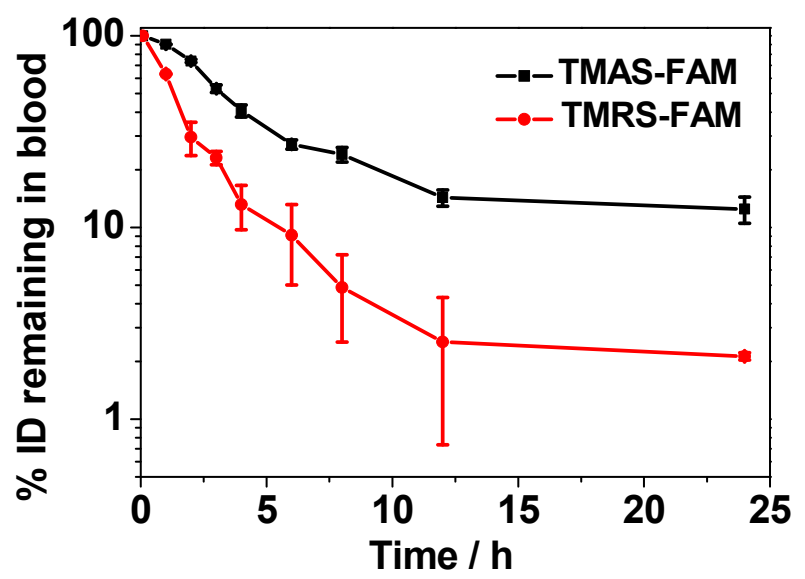

Figure S35. Blood clearance kinetics curves of TMAS-FAM and TMRS-FAM.

\section{In Vivo Photodynamic Therapy}

The tumor model was established by subcutaneously injecting 4T1 cells into mice. When the volume of the tumor reached $100 \mathrm{~mm}^{3}$, the $4 \mathrm{~T} 1$ tumor-bearing mice were randomly divided into 6 groups for different treatments ( $\mathrm{n}=5)$ : (1) PBS as a control, (2) PBS with $660 \mathrm{~nm}$ irradiation, (3) TMAS without irradiation, (4) free Ce6 with $660 \mathrm{~nm}$ irradiation, (5) TMRS with $660 \mathrm{~nm}$ irradiation, and (6) TMAS with $660 \mathrm{~nm}$ irradiation. The mice were intravenously injected with a dose of saline $(150 \mu \mathrm{L})$, free Ce6 $(150 \mu \mathrm{L}$, $0.25 \mathrm{mg} / \mathrm{mL}), \mathbf{T M R S}(150 \mu \mathrm{L}, 0.25 \mathrm{mg} / \mathrm{mL})$, and TMAS $(150 \mu \mathrm{L}, 0.25 \mathrm{mg} / \mathrm{mL})$ at day 0 , day 1 and day 2 . For the groups of $2,4,5$, and 6 , the mice were locally exposed to laser light $\left(660 \mathrm{~nm}, 1.4 \mathrm{~W} / \mathrm{cm}^{2}, 5 \mathrm{~min}\right)$ at $5 \mathrm{~h}$ post-injection. The body weight and the tumor size of each mouse were monitored every other day. The tumor volume (V) was calculated by the equation: Tumor volume $\left(\mathrm{mm}^{3}\right)=1 / 2 \times$ length $\times$ width ${ }^{2}$ (length is the longer dimension and width is the shorter dimension). At 14 day post-injection, the tumors, livers, and spleens of mice were collected for the H\&E staining. The H\&E staining images were imaged by Leica DFC450. All of the animal experiments were carried out under approved protocols of the Institutional Animal Care. 


\section{References}

[1] T. L. Hwang, A. J. Shaka, Water suppression that works. Excitation sculpting using arbitrary wave-forms and pulsed-field gradients. J. Magn. Reson. Ser. A 1995, 112, 275-279.

[2] A. J. Shaka, C. J. Lee, A. Pines, Iterative schemes for bilinear operators; application to spin decoupling. J. Magn. Reson. 1988, 77, 274-293.

[3] K. Wüthrich, M. Billeter, W. Braun, Polypeptide Secondary Structure Determination by Nuclear Magnetic Resonance Observation of Short ProtonProton Distances. J. Mol. Biol. 1984, 180, 715-740.

[4] J. Yao, V. A. Feher, B. F. Espejo, M. T. Reymond, P. E. Wright, H. J. Dyson, Stabilization of a Type VI Turn in a Family of Linear Peptides in Water Solution. J. Mol. Biol. 1994, 243, 736-753.

[5] J. Yao, H. J. Dyson, P. E. Wright, Three-dimensional Structure of a Type VI Turn in a Linear Peptide in Water Solution: Evidence for Stacking of Aromatic Rings as a Major Stabilizing Factor. J. Mol. Biol. 1994, 243, 754-766. 